\title{
Diazonium Modification of Inorganic and Organic Fillers for the Design of Robust Composites: A Review
}

\author{
M. Sandomierski ${ }^{1}$ (1) A. Voelkel $^{1}$
}

Received: 11 May 2020 / Accepted: 24 August 2020 / Published online: 2 September 2020

(c) The Author(s) 2020

\begin{abstract}
This review focuses on fillers modified with diazonium salts and their use in composites. We reviewed scientific publications and presented information about such diazonium-modified fillers as boron nitride, carbon fillers, cellulose, clay, silica, titanium dioxide, and zeolite. The fillers were divided into two groups. The first group includes those that form covalent bonds with the polymer, while the second includes those that do not form them. This review indicates a tremendous impact of filler modification using diazonium salts on the properties of composites. The review presents examples of the impact of filler on such properties as thermal conductivity, thermal stability, and mechanical properties (e.g., interfacial shear strength, compressive strength, flexural strength). The presented review indicates the enormous potential of composites with diazonium-modified fillers in control drug release, antistatic coatings, electrode materials, photocatalysts, bone tissue engineering scaffolds, fuel cell applications, abrasive tools, and electromechanical strain sensor. We hope that this review will help both research groups and industry in choosing fillers for given types of polymers and obtaining composites with even better properties.
\end{abstract}

Keywords Composites $\cdot$ Diazonium salt $\cdot$ Modification $\cdot$ Fillers

\section{Introduction}

The functionalization of various surfaces has attracted considerable attention from scientists for decades in many areas of application [1]. Particularly noteworthy is the surface modification of fillers used in many types of composites. The modification can be carried out using coupling agents. A coupling agent is a compound that functions at the interface to create a chemical bridge between filler and matrix [2]. Popular coupling agents that have been used so far are silanes, diazonium salts, titanates, and organophosphorus [3-7]. The selection of the appropriate modification allows for better distribution of the filler in the polymer matrix [8]. Besides, the modified filler can have strong interactions and even form covalent bonds with the polymer matrix. In this regard, many research teams are working on different types of modifications to obtain on the filler surface thin layers

M. Sandomierski

mariusz.sandomierski@put.poznan.pl

1 Institute of Chemical Technology and Engineering, Poznan University of Technology, ul. Berdychowo 4, 60-965 Poznań, Poland with better adhesion to the polymer, which will allow creating composites with better mechanical, thermal, and conductive properties $[9,10]$.

A useful type of modification that has been widely used for many years is a modification using diazonium salts (Fig. 1).

Diazonium salts are among the most versatile compounds in organic chemistry and are widely used in many reactions (e.g., Sandmeyer and Schiemann) [11]. The use of these salts allows the introduction into the compounds of such groups as: $\mathrm{OH}$, halogens, $\mathrm{CN}, \mathrm{H}$, etc.[12, 13]. The property that most restricts the use of simple diazonium salts (e.g., diazonium chlorides) is their instability and explosive nature, which affects the inability to store them [14, 15]. Furthermore, reactions with simple diazonium salts should be carried out in the same medium in which they were produced, which is often problematic and leads to low quality products. Due to this problem, a lot of research has been done to produce more complex diazonium salts that will be more stable. The research focused on counterions because they are responsible for the stability of the diazonium salt [4]. The first relatively stable diazonium compounds were diazonium tetrafluoroborates and hexafluorophosphates. However, they 


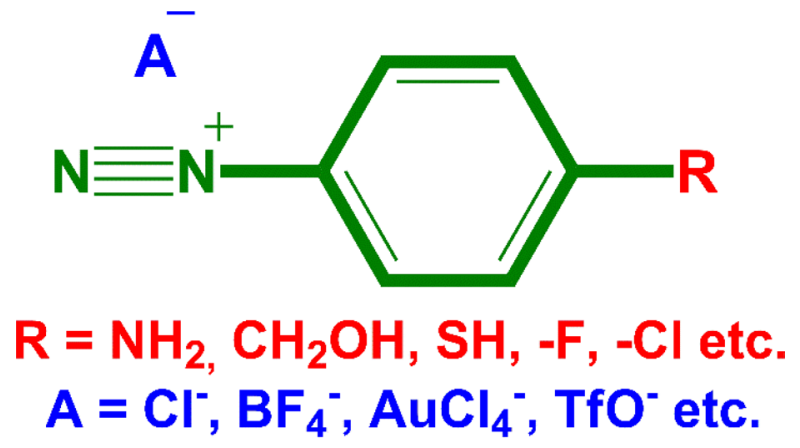

Fig. 1 Structure of the diazonium salt where $\mathrm{R}$ stands for substituents while A stands for charge-balancing anion Adapted from reference [12] with permission of the Royal Society of Chemistry

are often poorly soluble in water and, therefore, does not fit into the trend of green chemistry [16]. The most stable diazonium salts turned out to be the diazonium tosylates, tetrachloroaurates, and triflates [17-22]. These salts are well soluble in water, and some of them can be stored at room temperature even for several years. Improving the stability of the salts does not affect their high reactivity. High reactivity enabled the widespread use of diazonium salts in surface modification. Diazonium salts have been used in the modification of carbon, gold, diamond, copper, iron, and many other materials [23-29]. Surface-bound aryl layers allow changing the hydrophilic/hydrophobic and acid-base properties of modified materials [30]. The broad interest in this type of compound also results from their bifunctionality. This is because diazonium salts can be obtained from many types of aromatic amines having various reactive substituents $(\mathrm{R})$ in their structure [31]. Because of this, these salts have been used in areas such as medicine, electronics, and environmental protection $[32,33]$.

Diazonium surface modification is carried out using previously synthesized salts or using solutions of compounds synthesized in situ [34]. Diazotization can be carried out using $\mathrm{NaNO}_{2}$ in acidic aqueous solution or with t-butyl nitrite in acetonitrile. In the second stage of surface modification, it is necessary to reduce the salt [35]. The most commonly used methods of producing an active radical from diazonium salt are:

- Electrochemical reduction [36];

- Spontaneous reduction [37];

- Reduction using reducing reagents (hypophosphorous acid, ascorbic acid, and iron powder) [38];

- Photochemistry [39].

Surface modification of materials using diazonium compounds results in an extended aryl layer in which azo bonds may occur. (Fig. 2). If the reaction is not carried out under particular conditions, multilayer films are obtained by the

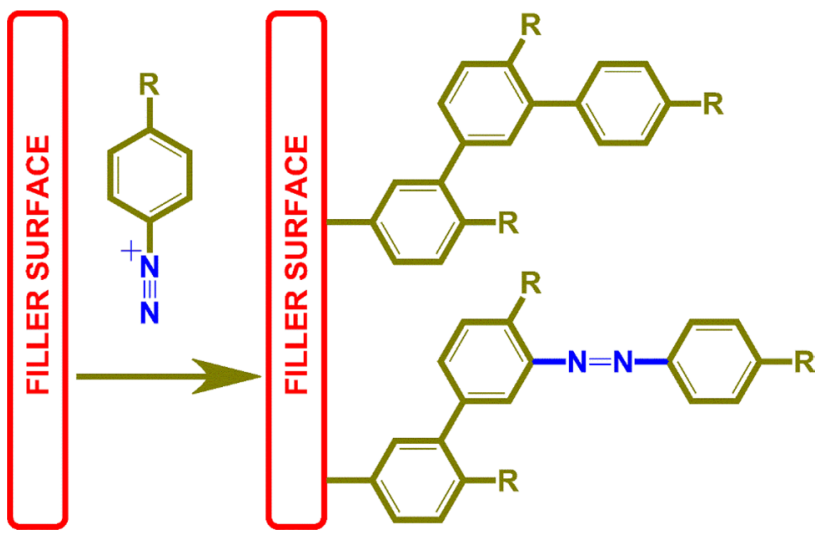

Fig. 2 Scheme of surface modification using diazonium salts (for simplicity, the monolayer was used in the rest of the publication Adapted from reference [12] with permission of the Royal Society of Chemistry

attack of the radicals on the first grafted aryl groups [40]. The diazonium modification, in some cases, also affects the structure of the modified material. For example, in modified graphene, due to the change in the hybridization of carbon from $\mathrm{sp}^{2}$ to $\mathrm{sp}^{3}$, its strain occurs [41]. Due to this, $\mathrm{sp}^{3}$-carbon is not in the plane of the flat graphene sheet (in our work, due to the simplification, these structures are presented as flat). Moreover, in these materials edge sites are more reactive than the basal plane during the diazonium modification.

We can easily change the properties of the aryl layer by changing the substituent in the aromatic ring. As the functional group ( $\mathrm{R}$ ) might be reactive, it is possible to graft polymers and other materials to already surface-bound aryl groups. Thanks to this property of aryl layers, it is possible to design given types of layers for a given application, which may be particularly attractive in composites.

In this article, we reviewed scientific publications in which diazonium salts have been used as filler surface modifiers. In this work, in order to simplify and increase its readability, fillers are generally understood as particles or fibers that were used as an additive to polymers in composites and nanocomposites. Although review articles and books on the extensive use of diazonium salts had previously appeared, they did not focus on modified fillers [4, 12, 42, 43]. In this work, we focus only on this subject to present the possibilities of using these modifiers in the composite industry in condensed way. This review presents information about such diazonium-modified fillers as boron nitride, carbon fillers, cellulose, clay, silica, titanium dioxide, and zeolite. These fillers were used as an addition to many types of polymers. We divided the fillers into two groups: (1) those that, after modification, form covalent bonds with the polymer, and (2) those that do not form them (Table 1). The formation of covalent bonds means that there are groups on the surface of the filler that can participate in the polymerization. The 
Table 1 Types of fillers modified with diazonium salts

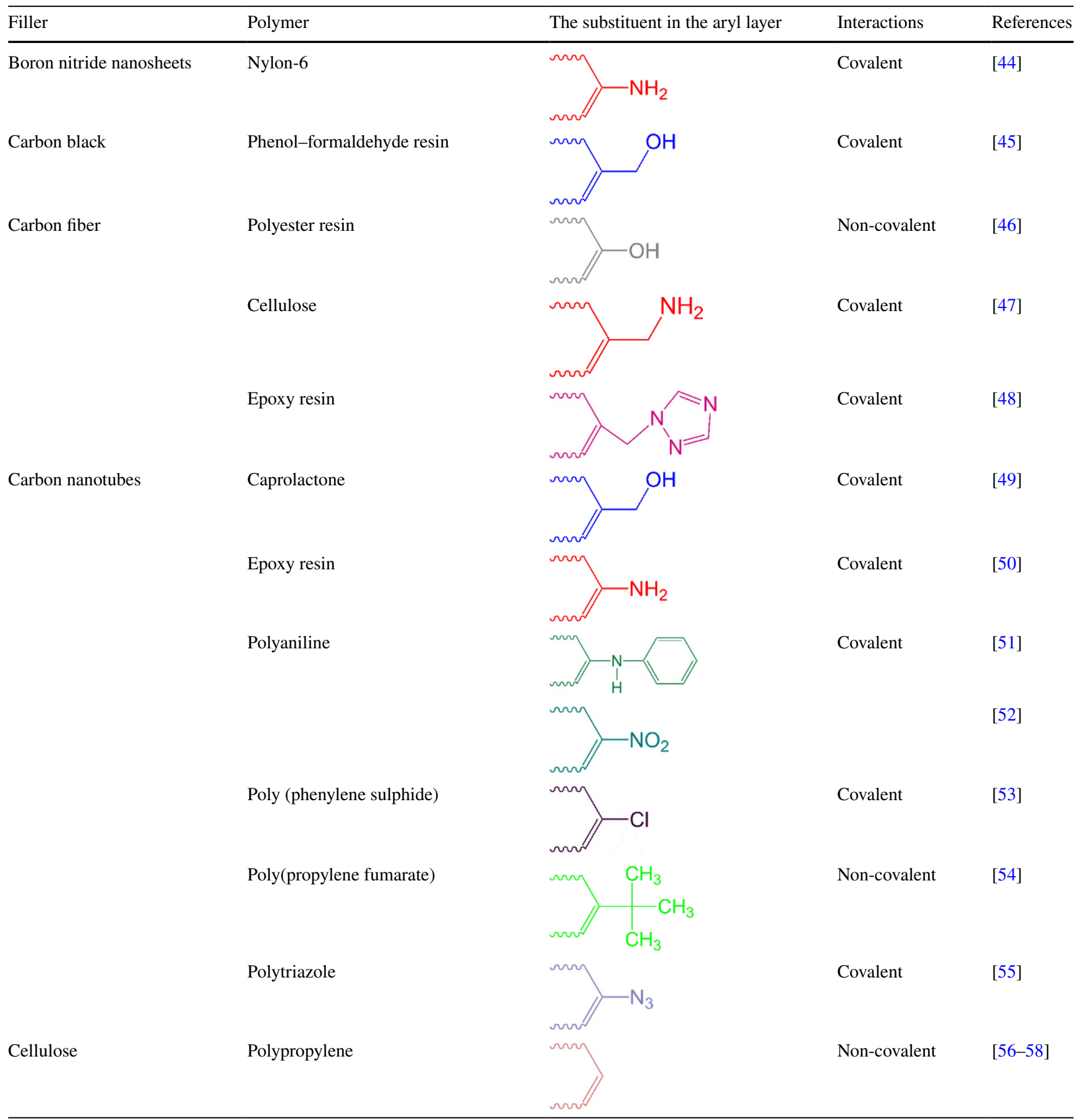


Table 1 (continued)

\begin{tabular}{|c|c|c|c|c|}
\hline Filler & Polymer & The substituent in the aryl layer & Interactions & References \\
\hline \multirow[t]{4}{*}{ Clay } & Ion imprinted polymer & nn & Covalent & {$[59,60]$} \\
\hline & Polyaniline / Epoxy resin & & Covalent & {$[61,62]$} \\
\hline & Poly(glycidyl methacrylate) & & Covalent & {$[63]$} \\
\hline & & nn & & {$[64]$} \\
\hline Fullerene & Sulfonated polyether ether ketone & nn & Non-covalent & {$[65]$} \\
\hline \multirow[t]{9}{*}{ Graphene } & Bismaleimide & $\sim n$ & Covalent & {$[66]$} \\
\hline & Epoxy resin & $-\mathrm{OH}$ & Covalent & [67] \\
\hline & Poly (acrylic acid) & $\Omega n$ & Covalent & {$[68]$} \\
\hline & Polyaniline & nn & Non-covalent & [69] \\
\hline & Polybenzimidazolium & & Non-covalent & [70] \\
\hline & Poly(ether ether ketone) & $\Omega n$ & Non-covalent & {$[71]$} \\
\hline & Polyimide & & Non-covalent & {$[72]$} \\
\hline & Polymethyl methacrylate & $n \Omega$ & Covalent & [73] \\
\hline & Polypyrrole & & Covalent & {$[74]$} \\
\hline
\end{tabular}


Table 1 (continued)

\begin{tabular}{|c|c|c|c|c|}
\hline Filler & Polymer & The substituent in the aryl layer & Interactions & References \\
\hline & Polystyrene & nn & Covalent & {$[75,76]$} \\
\hline & & & Covalent & {$[77]$} \\
\hline & Poly(styrene-co-acrylonitrile) & $n$ & Non-covalent & [78] \\
\hline & Poly(vinyl alcohol) & $n$ & Non-covalent & [79] \\
\hline & Poly(vinylidene fluoride) & $\Omega \sim$ & Non-covalent & {$[80]$} \\
\hline Silica & Phenol-formaldehyde resin & $n n$ & Covalent & {$[81,82]$} \\
\hline $\begin{array}{l}\text { Ruthenium oxide / } \\
\text { Titanium oxide }\end{array}$ & Polyaniline & & Covalent & [83] \\
\hline Titanium dioxide & Polyaniline & $\sim$ & Covalent & [84] \\
\hline \multirow[t]{2}{*}{ Zeolite } & Phenol-formaldehyde resin & nns & Covalent & {$[85,86]$} \\
\hline & Methacrylic resin & norn & Covalent & [87] \\
\hline
\end{tabular}

effect of the modified filler on improving properties of composites has also been extensively described.

\section{Influence of Substituent Position in the Diazonium Salt}

The active substituent in a diazonium salt should be in the para position because the use of a substituent in a different position causes steric hindrance and, therefore, the active radical cannot attach to the modified surface very easily
(Fig. 3) [85]. A layer will be created; but, the effectiveness of the modification will be low. On the other hand, the created layer due to substituents directed "to the surface" will not react as easily with the polymer also due to steric hindrance. This was previously described in detail in the work of Combellas et al. [88]. This publication proves that substituents in the ortho position hinder reaction with the surface. In the case of a substituent in the meta position, its size has a significant influence on the effectiveness of the modification. The use of a large substituent affects the formation of a monolayer. 


\section{Diazonium Modified Fillers that Form Covalent Bonds with the Polymer}

The formation of covalent bonds between the matrix and the filler allows a composite with better mechanical properties. The energy in this type of composite is better distributed to the entire volume of the composite. Such composites also have better-conducting properties.

\subsection{Boron Nitride Nanosheets}

Boron nitride nanosheets were used as a filler in polyamide-6 (PA6) [44]. The primary purpose of the modification was to improve the thermal conductivity of boron nitride nanosheets/polyamide-6 composite. Boron nitride nanosheets were functionalized with amino groups via a two-step reaction. In the first step, the filler was hydroxylated in a strongly alkaline environment at elevated temperature $\left(180^{\circ} \mathrm{C}\right)$. Then the diazonium salt, reduced under the influence of hydrochloric acid and iron, was attached to the hydroxyl groups that were formed earlier on the surface of boron nitride nanosheets. Composites were prepared by simple melt-blending, and covalent bonds were formed between the amino groups from the aryl layer and the carboxyl groups

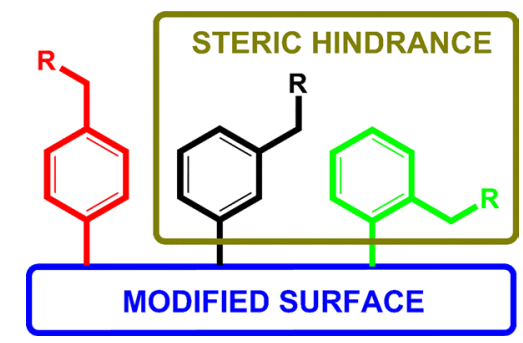

Fig. 3 Possible substitution of the substituents in the aryl layer from the polyamide-6 chains (Fig. 4). Composites with modified filler had improved thermal conductivity, thermal stability, and mechanical properties compared with the composites with the unmodified filler at the same filler content. The initial decomposition temperature of the composites with modified boron nitride nanosheets was nearly. $100{ }^{\circ} \mathrm{C}$ higher than that of composites with unmodified boron nitride nanosheets. The flexural modulus increased by $\sim 50 \%$, while the impact strength increased by $\sim 92 \%$. All these changes testify to the significant influence of the thin aryl layer on the properties of polyamide- 6 composites. All these properties indicate that these composites have great potential as thermally conducting engineering plastics.

\subsection{Carbon Black}

Diazonium-modified carbon black that forms covalent bonds with the organic matrix was used as a filler in the phenol-formaldehyde resin [45]. This filler was also used in abrasive tools, which additionally contained abrasive grains. The main aim of the modification was to improve the mechanical properties of the final composite and to reduce toxic cross-linking agents. Diazonium modification allows the incorporation of hydroxymethyl groups, which are responsible for the cross-linking of phenol-formaldehyde resins. Due to their introduction at the surface, these fillers take part in the cross-linking reaction. The use of a modified filler resulted in a $126 \%$ improvement in flexural strength for the phenol-formaldehyde resin composite and $1100 \%$ for the abrasive tools compared to the composite with unmodified filler. The increase in flexural strength is related to the resulting covalent bonds between the resin and the modified filler (Fig. 5). The use of this type of filler reduces the amount of cross-linking agent and the toxicity of the composite. Therefore, it can be stated that the application of modified carbon
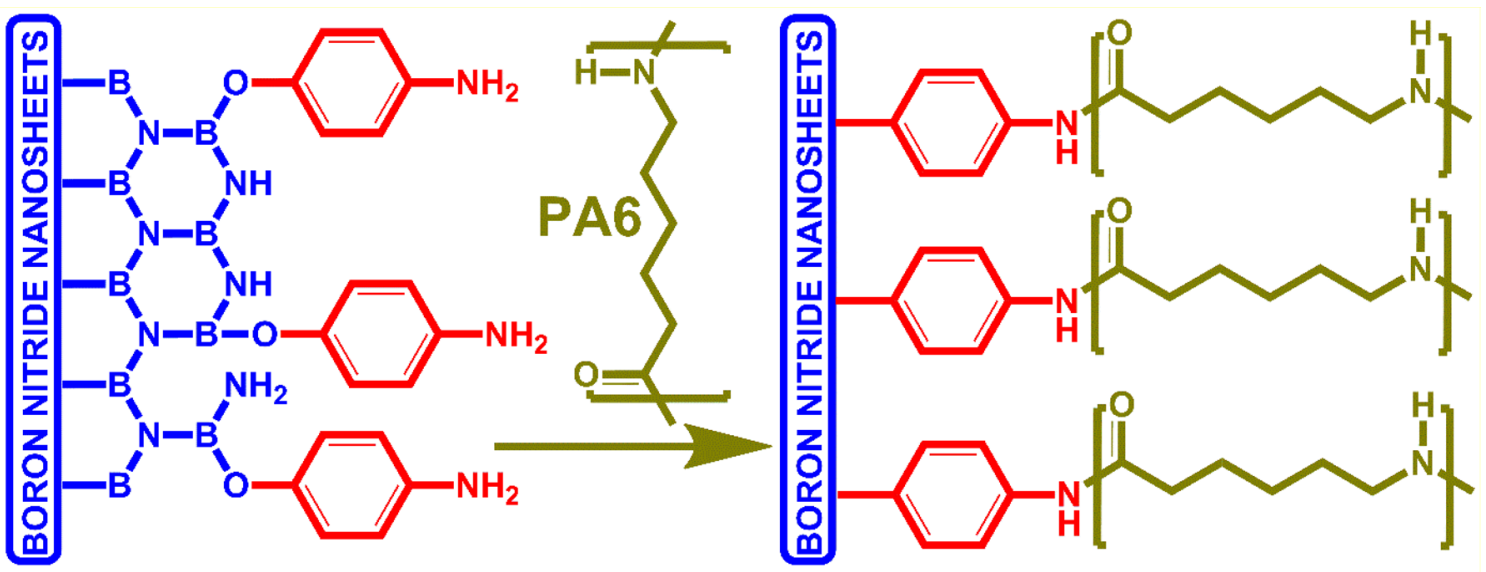

Fig. 4 Scheme for modified boron nitride nanosheets/polyamide-6 composite preparation and the formation of covalent bonds between the amino groups from the aryl layer and the carboxyl groups from the polymer Adapted from reference [44] with permission of ACS Publications 
black improves the properties of phenol-formaldehyde resin composites and abrasive tools.

\subsection{Carbon Fiber}

\subsubsection{Diazonium-Modified Carbon Fiber/Cellulose Propionate Composite}

The main aim of the carbon fiber modification was to improve interfacial adhesion between cellulose propionate and the carbon fiber surface and preparation of green cellulose-based carbon fiber reinforced polymers [47]. Diazonium modification allows the incorporation of amino groups, which take part in a reaction with a tosylated cellulose derivative (Fig. 6). The use of a modified filler affected a significant increase in interfacial shear strength compared to the composite with unmodified carbon fiber.

\subsubsection{Diazonium-Modified Carbon Fiber/Epoxy Resin Composite}

Triazole-functionalized carbon fibers were prepared by arylation with diazonium salts generated in situ [48]. The incorporated triazole groups may initiate a local curing reaction of the epoxy resin and thus may be covalently anchored to the epoxy network during the curing process. The results indicated that modified carbon fibers significantly improve dispersibility in the epoxy resins compared to the unmodified carbon fiber. Modification positively influenced the ability of the filler for toughening the epoxy resin and thermal properties of composites. Besides, the modification increased the critical stress intensity factor by $41 \%$ and the critical strain energy release rate by $80 \%$.

\subsection{Carbon Nanotubes}

\subsubsection{Diazonium Modified Carbon Nanotubes/ Polycaprolactone Composite}

Diazonium modification with 4-hydroxymethyl benzene diazonium salt allows the incorporation of hydroxymethyl groups. These groups take part in the polymerization of the caprolactone (Fig. 7) [49]. Hydroxyl groups that were generated were used to initiate the ring-opening polymerization of the caprolactone. Polycaprolactone is a biodegradable and biocompatible polymer and is used in tissue engineering. These results indicate the enormous potential of using modified carbon nanotubes for biomedical applications. Unfortunately, conductivity and mechanical as well as thermal properties for these materials have not yet been tested.

\subsubsection{Diazonium-Modified Carbon Nanotubes/Epoxy Composite}

In this work, 4,4' diamino diphenyl sulfone was used as amine for the in situ generation of the diazonium salt [50]. Single-walled carbon nanotubes were modified to improve both the dispersibility and interface interaction with epoxy resin. Covalent bonds were formed between the filler and the matrix during cross-linking (Fig. 8). The composite with the modified filler turned out to be more homogeneous. Moreover, modified fillers do not have such a significant influence as unmodified fillers on the viscosity of the resin what is advantageous in processing the composite. Unfortunately, conductivity and mechanical properties for these materials have not yet been tested.

\subsubsection{Diazonium-Modified Carbon Nanotubes/Polyaniline Composite}

Surface modification for these composites can be performed using two types of diazonium salts.

In the first example, during modification, an aryl layer with diphenylamine groups was created [51]. The composites with modified fillers were prepared in two steps. In the first step, ammonium persulfate (APS) is added to the solution of modified filler and aniline. As a result, anilinium and diphenylamine cations are formed. In the second step, monomers were attached to the activated layer to form a polyaniline layer (Fig. 9). The conductivity of polyaniline without a filler is $0.01 \mathrm{~S} \cdot \mathrm{cm}^{-1}$. The addition of modified carbon nanotubes increases the conductivity significantly. The conductivity value of a composite with a modified filler is $12.43 \mathrm{~S} \cdot \mathrm{cm}^{-1}$ and is almost twice that for composite with unmodified filler $\left(7.30 \mathrm{~S} \cdot \mathrm{cm}^{-1}\right)$.

In the second example, the surface functionalization of carbon nanotubes was conducted using 4-nitrobenzenediazonium salt [52]. In the first step, carbon nanotubes were functionalized with 4-nitrophenyl groups. The nitro groups were further reduced electrochemically to amino groups. Polyaniline was then grafted onto the surface of the obtained aminophenyl-modified carbon nanotubes (Fig. 10). The resulting polyaniline/modified carbon nanotubes composites exhibit significantly improved stability and higher capacitance values. The capacitance of the composites with the modified filler is two-times higher than the composites with the unmodified filler. Both studies indicate the potential use of these composites in supercapacitors.

\subsubsection{Diazonium-Modified Carbon Nanotubes/ Poly(p-Phenylene Sulphide) Composite}

Diazonium modification using 4-chlorobenzenediazonium salt leads to the incorporation of chlorophenyl groups. These 


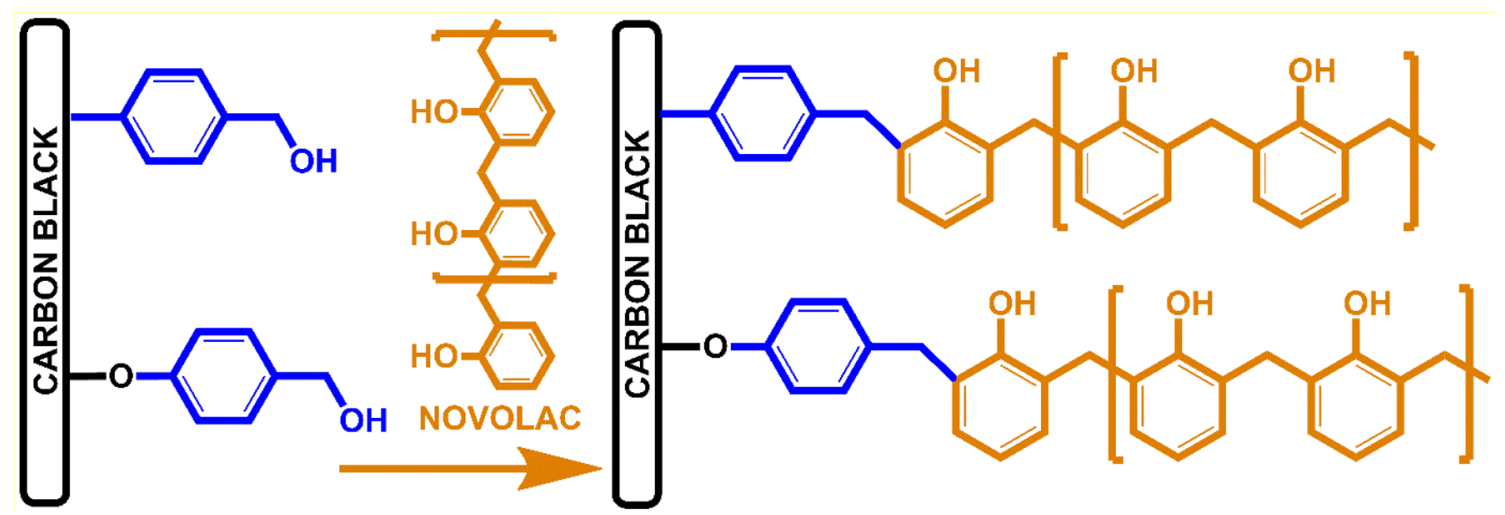

Fig. 5 Scheme for modified carbon black/phenol-formaldehyde resin composite preparation and formation of covalent bonds between the hydroxymethyl group from the aryl layer and the aromatic ring from the resin

groups take part in the polymerization of poly(p-phenylene sulfide) in the presence of $\mathrm{Na}_{2} \mathrm{~S}$ and 1,4- dichlorobenzene (Fig. 11) [53]. The resulting poly(p-phenylene sulphide)/ modified carbon nanotube composites exhibit significantly improved thermal stability (up to $17^{\circ} \mathrm{C}$ ), crystallinity (up to $11 \%$ ), and improved mechanical properties. In contrast, electrical properties do not change. The addition of the modified filler increases the tensile strength by $80 \%$ and Young's modulus by $100 \%$ compared to composites with unmodified carbon nanotubes.

\subsubsection{Diazonium-Modified Carbon Nanotube/Polytriazole Composite}

Nanotubes were functionalized with 4-azidobenzenediazonium salt [55]. Diazonium modification leads to the incorporation of azidophenyl groups, which take part in the polymerization of polytriazole in the presence of (O-propargyl) diethylene glycol and 1,3-diazidopropane (Fig. 12). Unfortunately, conductivity, mechanical and thermal properties for these materials have not been tested.

\subsection{Graphene}

\subsubsection{Diazonium-Modified Graphene Nanosheets/ Bismaleimide Composite}

Nanosheets were functionalized with 4-aminobenzenediazonium salt [66]. Diazonium modification incorporated amino groups, which take part in the polymerization of bismaleimide (Fig. 13). Bismaleimide/modified graphene nanosheets composites exhibit significantly improved impact strength (up to 39\%) and a slightly improved flexural strength.

\subsubsection{Diazonium-Modified Graphene Sheets/Epoxy Resin Composites}

Graphene sheets were modified with 4-hydroxyethyl benzene diazonium salt [67]. Then, 4,4'-methylene diphenyl diisocyanate (MDI) and 4,4'-methylenedianiline (MDA) were attached to the hydroxyl moieties. (Fig. 14). From this reaction, many amine groups were formed on the surface, and these groups formed covalent bonds with the epoxy resin. Long-chain aromatic amines on the filler surface were chemically similar to the curing agent. As a result, epoxy/modified graphene sheet composites exhibited significantly improved fracture toughness (up to $94 \%$ ) and flexural strength (up to $92 \%$ ). The obtained results can be used in the preparation of light, durable, and robust polymer nanocomposites.

\subsubsection{Diazonium-Modified Graphene/Poly(Acrylic Acid) Hydrogel Composite}

Graphene was functionalized with 4-carboxybenzenediazonium salt [68]. Diazonium modification allows for the incorporation of carboxyl groups, which take part in a RAFT polymerization of poly(acrylic acid) in the presence of a cross-linking agent (Fig. 15). The RAFT agent is covalently coupled by esterification with benzoic acid groups from the aryl layer. The resulting graphene/poly(acrylic acid) hydrogel is $\mathrm{pH}$-sensitive and more mechanically elastic than hydrogel without the filler. Due to the sensitivity of the hydrogel to $\mathrm{pH}$, it can be used for controlled drug release. Doxorubicin was chosen as a model drug and loaded into the hydrogels. The drug loading and release experiment indicated that this hydrogel could be used to control drug release efficiently. 


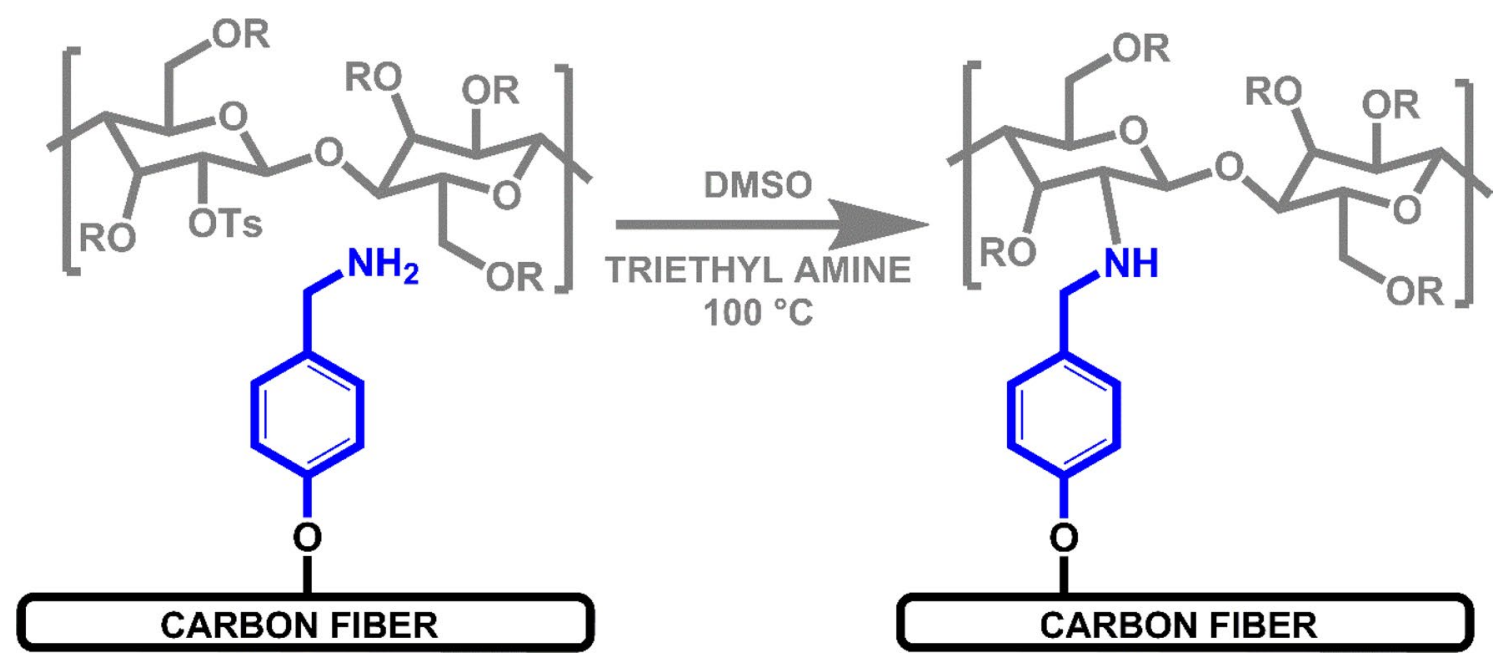

Fig. 6 Scheme for modified carbon fiber/cellulose propionate composite preparation and formation of a covalent bond between the amino group from the aryl layer and the tosylated group from cellulose Adapted from reference [47] with permission of Royal Society of Chemistry

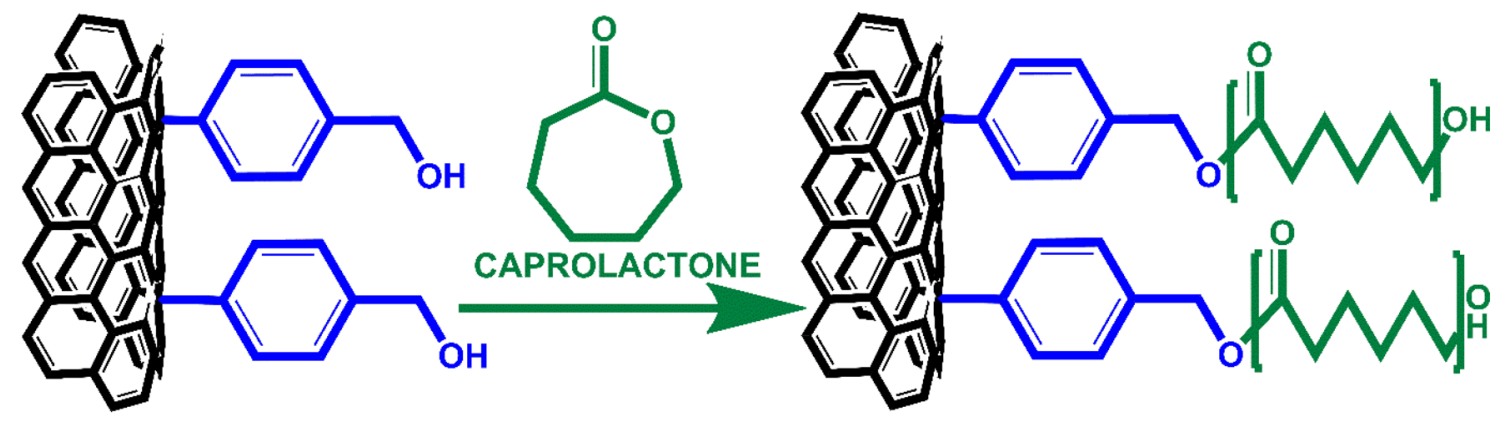

Fig. 7 Scheme for modified carbon nanotubes/polycaprolactone composite preparation and formation of covalent bonds between hydroxyl groups from the aryl layer and the caprolactone ring Adapted from reference [49] with permission of ACS Publications

\subsubsection{Diazonium-Modified Graphene Nanoplatelets/ Poly(Methylmethacrylate) (PMMA) Composite}

Modification with 4-amino benzene diazonium salt was performed to improve the compatibility of graphene nanoplatelets with polymer matrix by strong covalent filler-polymer interactions [73]. Thus, diazonium modification allows the incorporation of amino groups, which take part in the polymerization of PMMA through amidation between the amino groups and PMMA chains (Fig. 16). The addition of a modified filler increases the elastic modulus, strength, and strain at break of PMMA, whereas the incorporation of unmodified filler showed reduced levels of reinforcement. Besides, due to the addition of a modified filler, the glass transition temperature increased by $15{ }^{\circ} \mathrm{C}$ while the onset of decomposition by $29^{\circ} \mathrm{C}$ compared to pure PMMA.

\subsubsection{Diazonium-Modified Graphene Nanosheets/ Polypyrrole (PPy) Composite}

The next example of the use of modified graphene nanosheets was their application as a filler in a composite with PPy [74]. Graphene nanosheets were functionalized with 4-aminobenzenediazonium salt. Diazonium modification allows the incorporation of amino groups, which takes part in the polymerization of pyrrole (Fig. 17). Graphene nanosheets/PPy composite possess high conductivity at room temperature (up to $27 \mathrm{~S} \mathrm{~cm}^{-1}$ ). These values are higher than for pure polymer and polymer filled with unmodified graphene. Composites filled with modified fillers were also exhibited excellent electrochemical stability even after 1000 cycles. Due to the beneficial properties of these composites, they have great potential as antistatic coatings and electrode materials. 


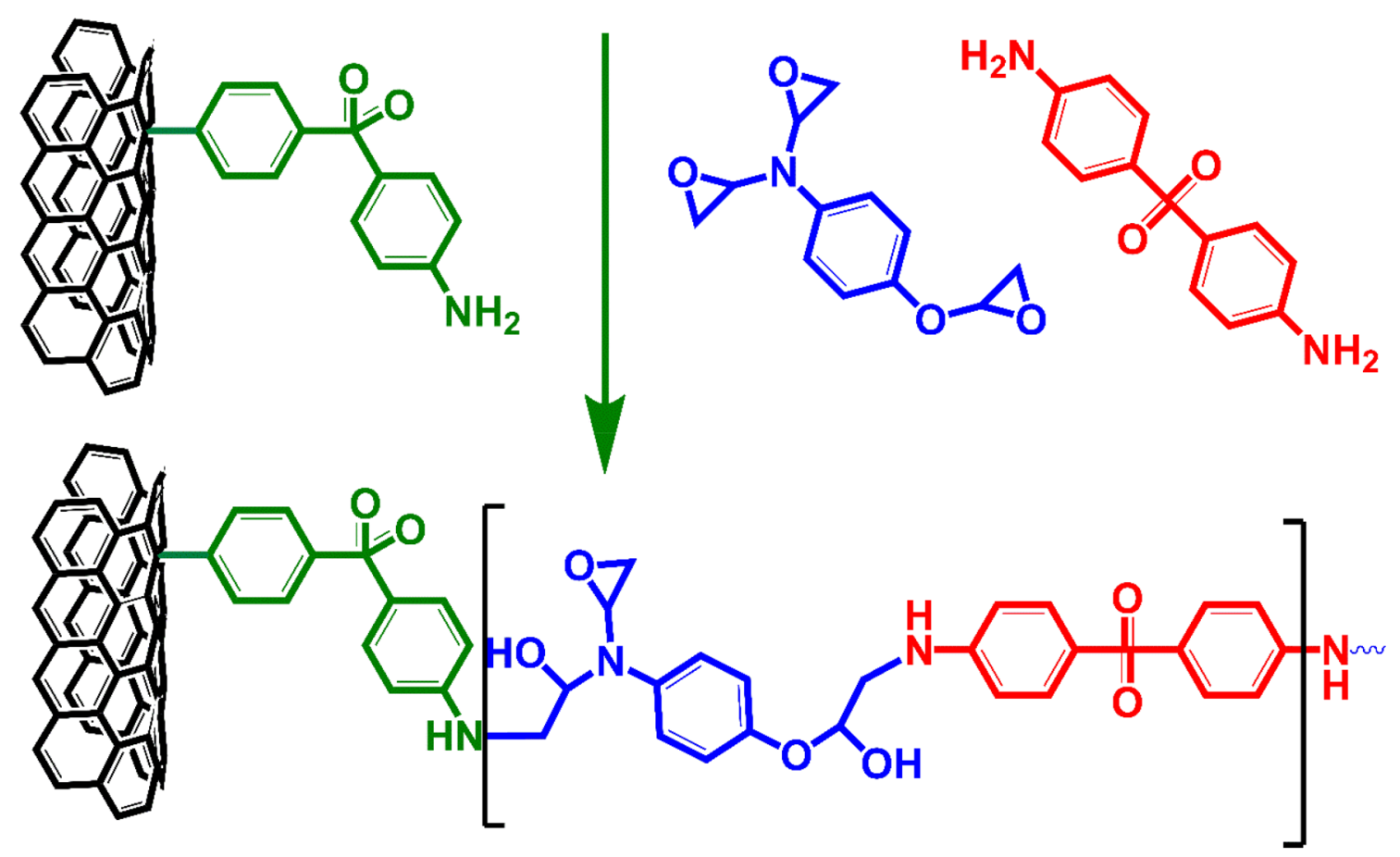

Fig. 8 Scheme for modified carbon nanotubes/epoxy composite preparation and formation of covalent bonds between the amino group from the aryl layer and the epoxide group

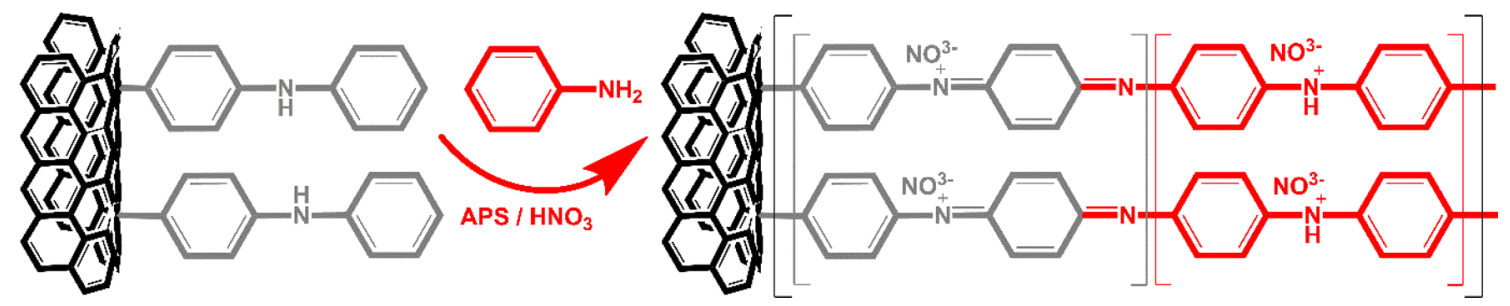

Fig. 9 Scheme for modified carbon nanotubes/polyaniline composite preparation and the formation of covalent bonds between diphenylamine groups and aniline Adapted from reference [51] with permission of Elsevier

\subsubsection{Diazonium Modified Graphene Nanosheets/ Polystyrene (PS) Composite}

Diazonium-modified graphene nanosheets were also used as a composite with polystyrene $[75,76]$. In the first two cases, graphene nanosheets were functionalized with 4-hydroxyethyl benzene diazonium salt and then linked with PS chains by atom transfer radical polymerization. The addition of a modified filler influenced the increase in the glass transition temperature (up to $18{ }^{\circ} \mathrm{C}$ ) compared to the pure PS. Besides, the composites showed an increase in tensile strength (up to $70 \%$ ) and Young's modulus (up to 57\%) relative to pure PS.

The third example is the use of sulfonated reduced graphene oxide in polystyrene-based diazonium salt [77]. Negatively charged filler was modified by diazonium salt of sulfanilic acid. The UV light irradiation achieved the cross-linking between filler and polymer. The formation of covalent bonds was verified by ATR, XPS, and contact angle measurement. The graphene nanosheets were found to be homogeneously distributed in the composite. The specific capacitance of composites was $150.4 \mathrm{~F} / \mathrm{g}$. Because of the cross-linked structure, this composite exhibited superior cyclic stability with a $97 \%$ capacitance retention even after 10000 charge - discharge cycles. The obtained results indicate the enormous potential of these composites as supercapacitor electrodes and potential material in energy storage. 


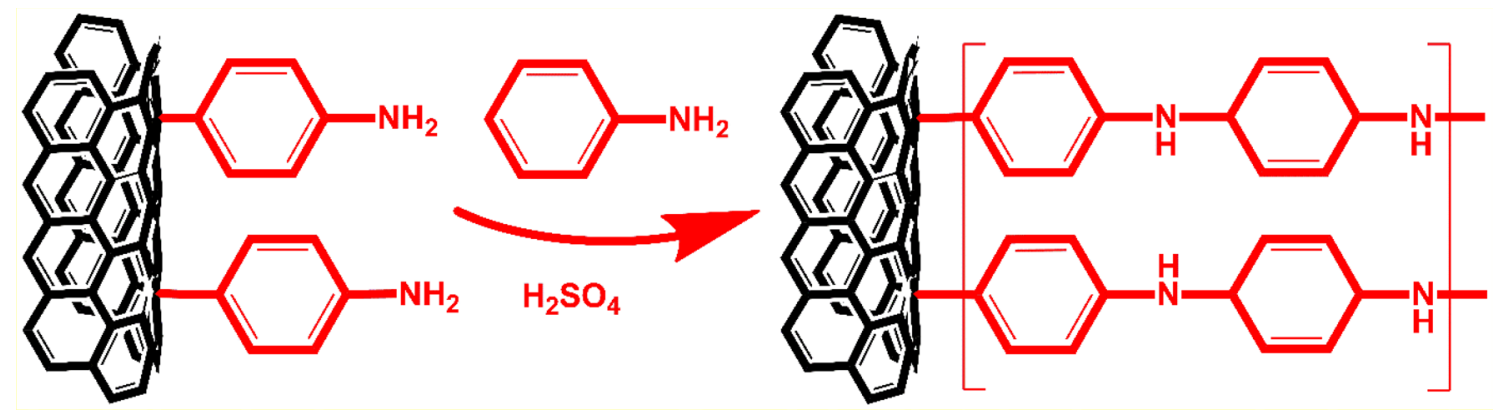

Fig. 10 Scheme for modified carbon nanotubes/polyaniline composite preparation and formation of the covalent bond between amino groups and aniline Adapted from reference [52] with permission of Wiley
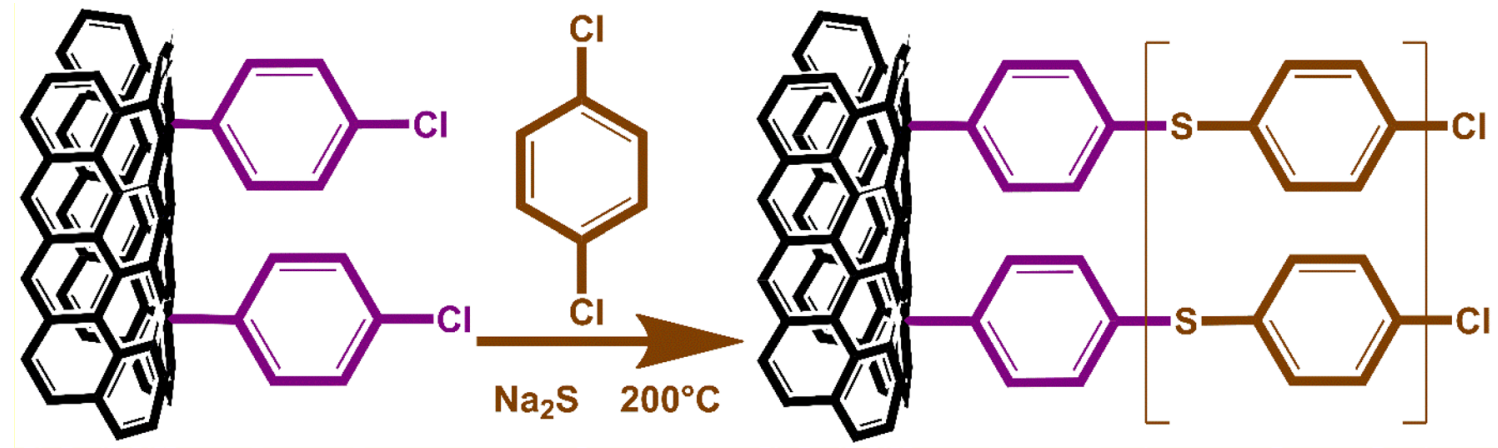

Fig. 11 Scheme for modified carbon nanotubes/poly(p-phenylene sulphide) composite preparation and covalent bond formation Adapted from reference [53] with permission of the Royal Society of Chemistry

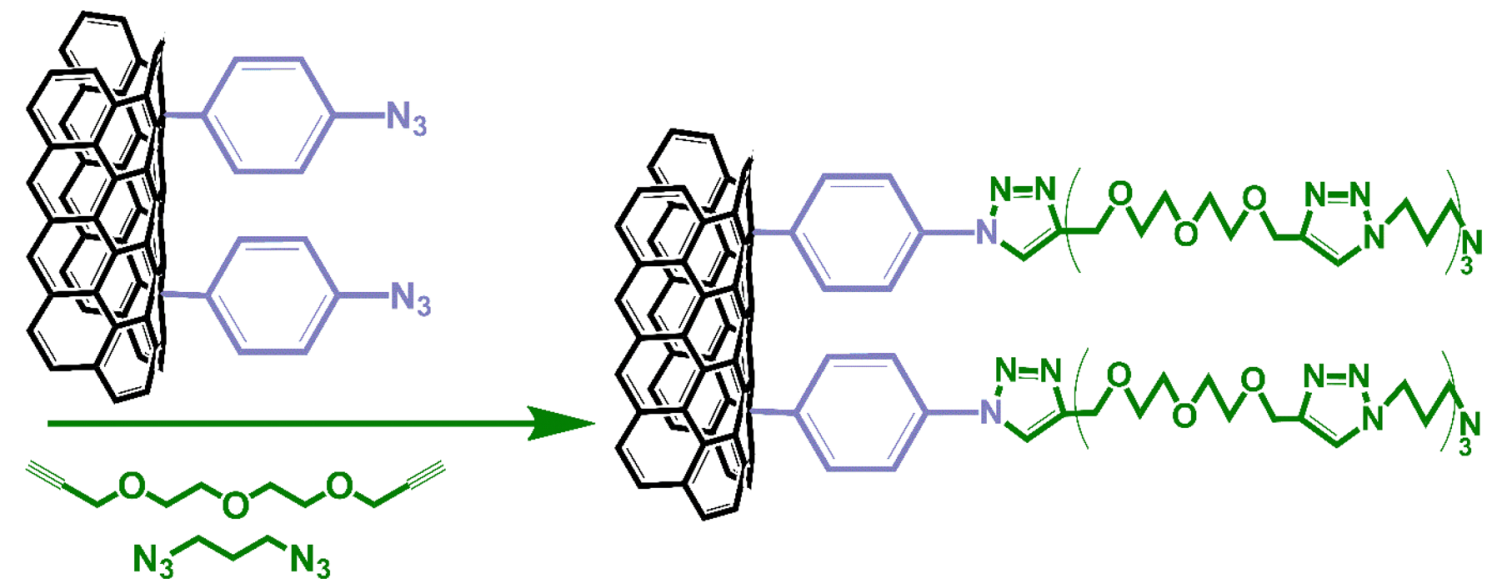

Fig. 12 Scheme for modified carbon nanotubes/polytriazole composite preparation and covalent bond formation Adapted from reference [55] with permission of Wiley 
12

Journal of Inorganic and Organometallic Polymers and Materials (2021) 31:1-21

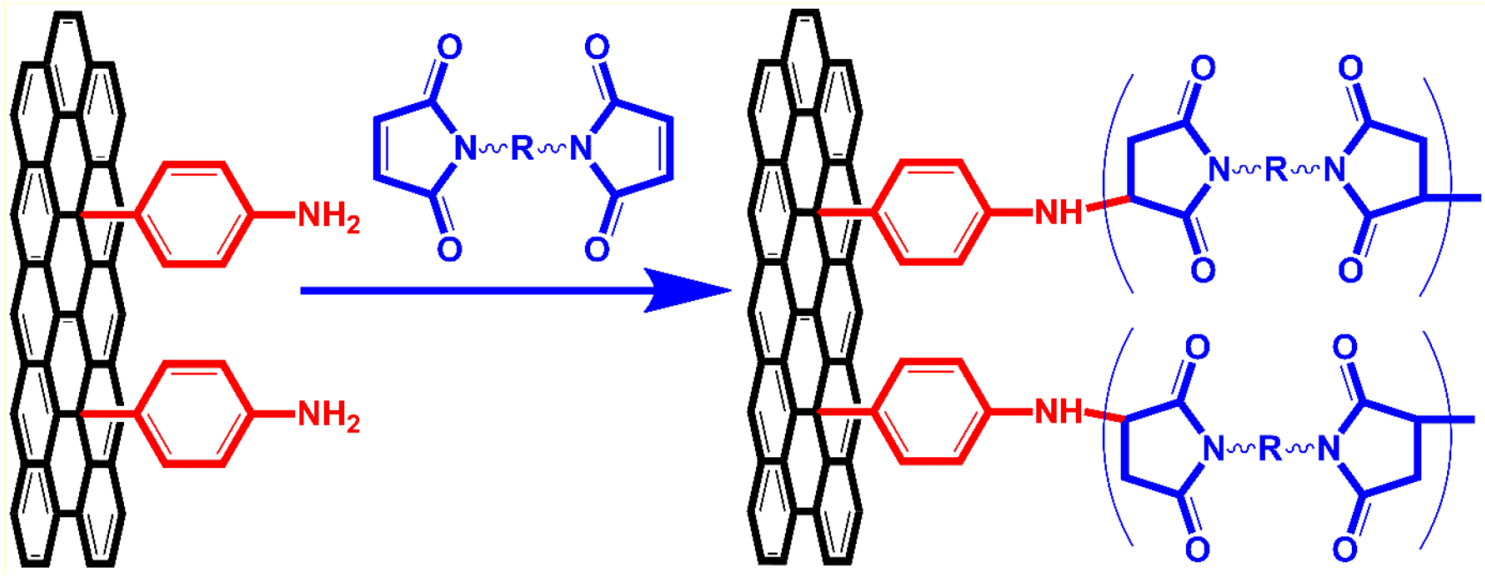

Fig. 13 Scheme for modified grapheme nanosheets/bismaleimide composite preparation and formation of covalent bonds between amino groups and double bonds from bismaleimide Adapted from reference [66] with permission of Elsevier

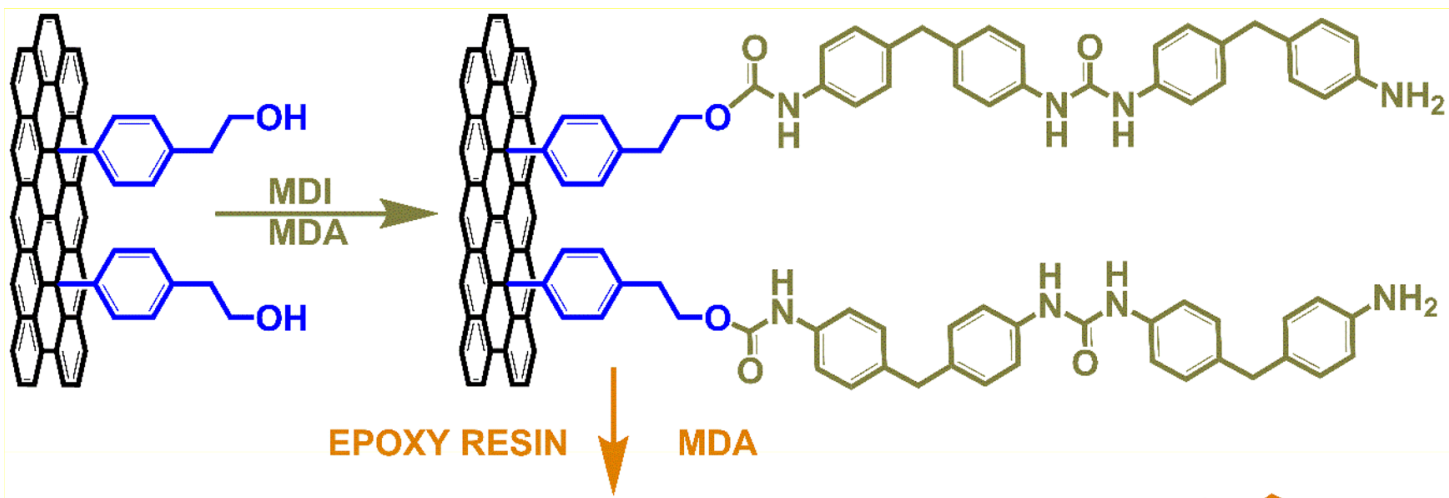

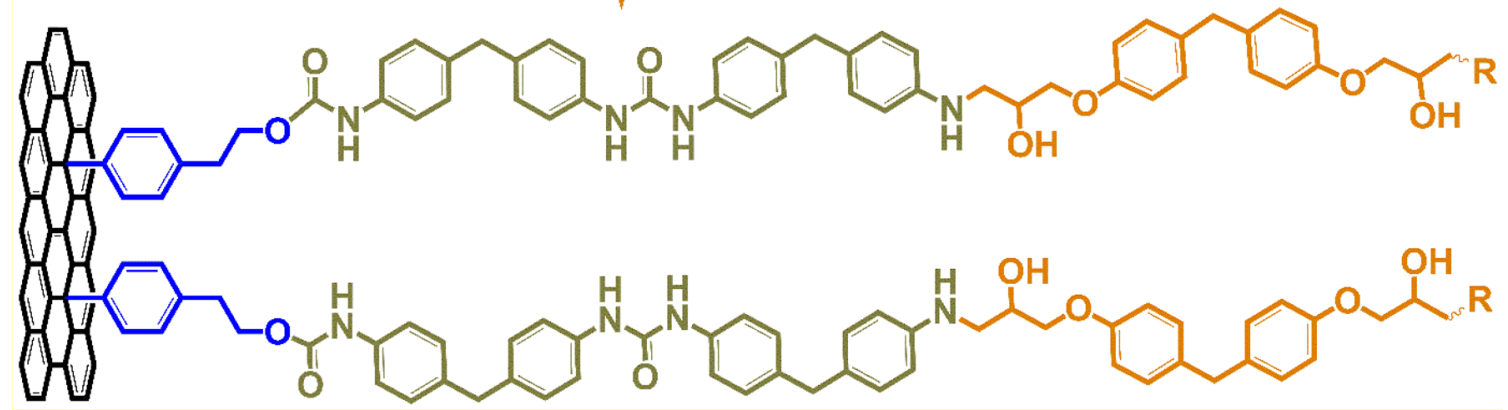

Fig. 14 Scheme for modified grapheme sheets/epoxy resin composite preparation and formation of covalent bonds Adapted from reference [67] with permission of the Royal Society of Chemistry

Springer 


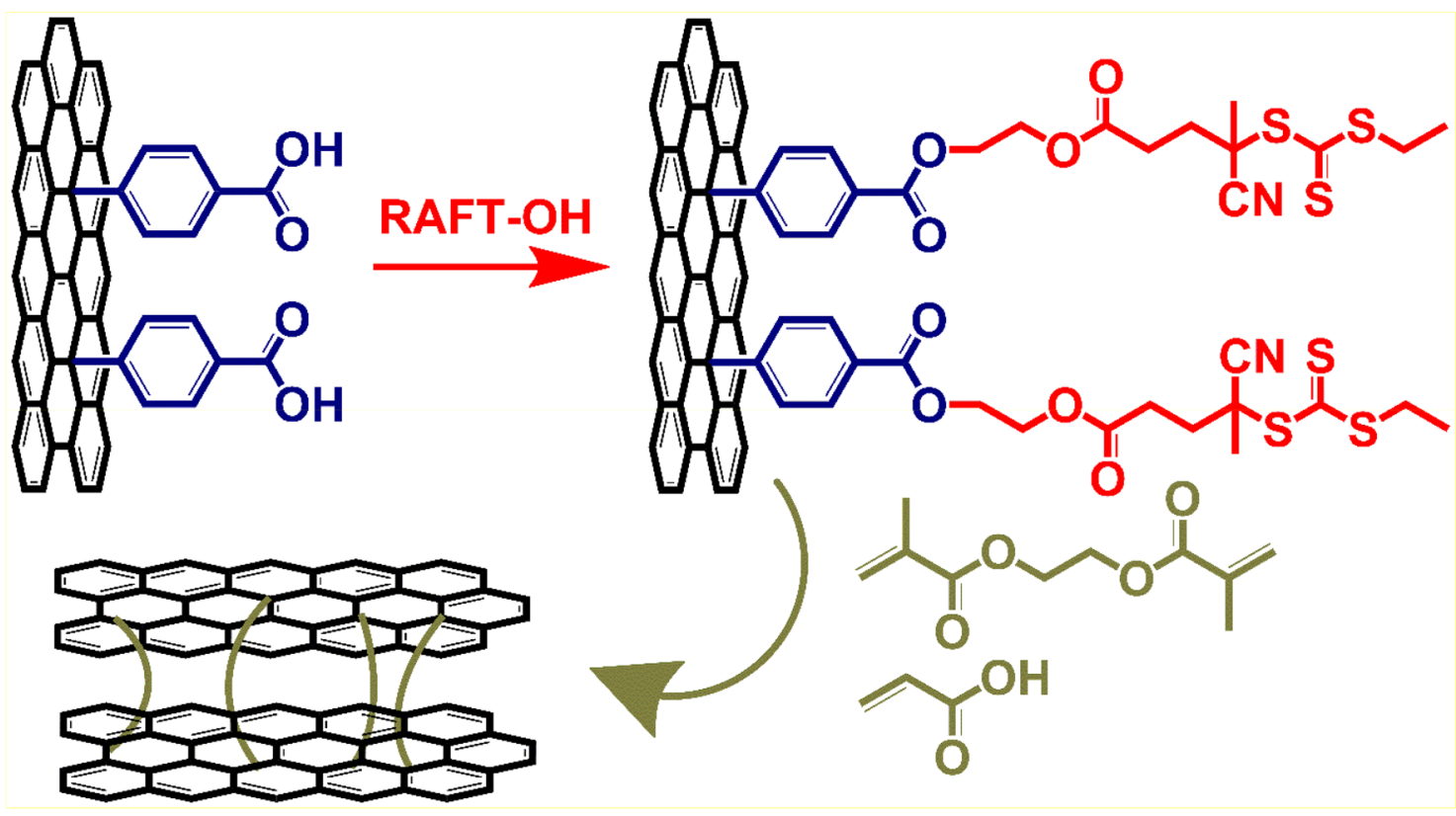

Fig. 15 Scheme for modified graphene/poly(acrylic acid) hydrogel composite preparation and formation of covalent bonds Adapted from reference [68] with permission of Elsevier

\subsection{Clay}

\subsubsection{Diazonium-Modified Montmorillonite/lon-Imprinted Polymer Nanocomposite}

The first and second example of using a clay filler is the use of montmorillonite to obtain ion-imprinted polymers $[59,60]$. In both cases, montmorillonite was modified with dimethylaminobenzenediazonium salt. The use of this salt allowed the introduction of dimethylamino groups that are involved in polymerization. Nanocomposites were prepared by a radical photopolymerization process, but other monomers were used.

The nanocomposite in the first publication was used for the selective removal of lead (II) [59]. Nanocomposites with modified filler remove about 180-times more lead (II) than with unmodified filler. Besides, the composites were selective and removed more than 4-times more lead ions than iron and zinc ions.

Nanocomposite, in the second example, was used for selective removal of copper (II) in an aqueous solution [60]. Nanocomposites with modified filler removed more copper (II) than with unmodified filler. Also, the filled nanocomposites captured several times more copper compared to zinc, lead, and iron ions.

Both studies confirmed the high efficiency of diazonium salts as polymerization initiators in the preparation of ionimprinted polymer nanocomposites. They also indicate the enormous potential of this type of material in the selective purification of solutions containing metal ions.

\subsubsection{Diazonium-Modified Bentonite/Epoxy Nanocomposite}

The third and fourth examples are composites with epoxy resin $[61,62]$. Bentonite fillers were modified with a 4-diphenylamine diazonium salt. Then, a polyaniline layer was formed on its surface by in situ oxidative polymerization of aniline (Fig. 8). The filler was not modified just to make the clay better dispersed. The resulting layer also acted as a curing agent for the epoxy resins, which was confirmed because the curing activation energy decreased as the amount of filler increased.

The addition of a modified filler had a significant impact on the increase of dielectric constant (from 7.3 to 14.3) [61]. Improvement in tensile and flexural strength shows that the nanocomposite with modified filler can be considered ideal for high-performance applications. Also, the fracture toughness of the nanocomposites increased by $210-220 \%$, which confirms that the resulting layer on the surface of the filler acts as an effective stress transfer agent. In summary, a diazonium/polyaniline layer has an essential effect on the improvement of interfacial properties and adhesion.

Bentonite/ $\mathrm{Fe}_{3} \mathrm{O}_{4}$ filler in the second publication was used after diazonium modification and polyaniline formation [62]. The addition of the modified filler improved the 


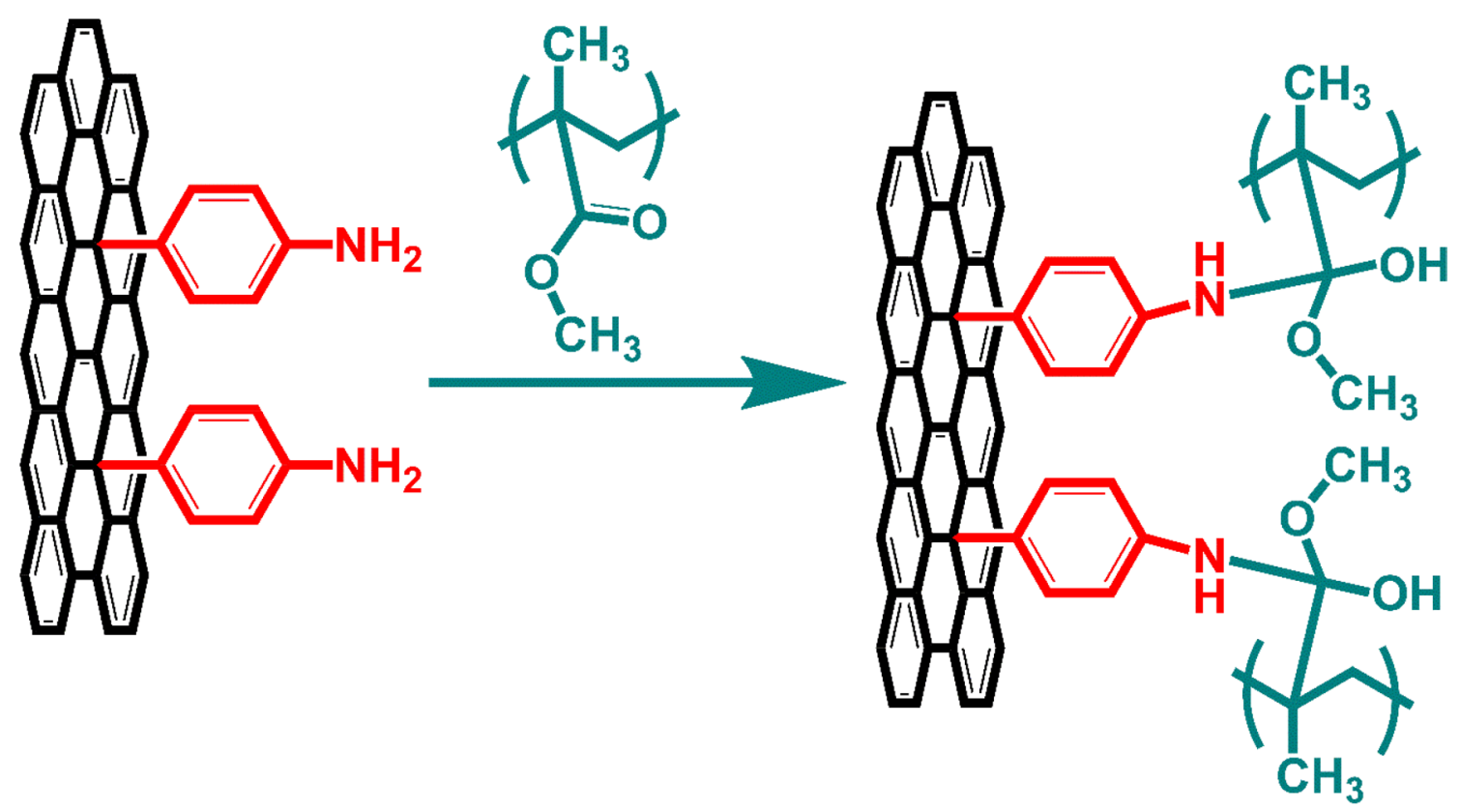

Fig. 16 Scheme for modified graphene nanoplatelets/PMMA composite preparation and formation of covalent bonds between amino groups and PMMA through amidation Adapted from reference [73] with permission of Elsevier)

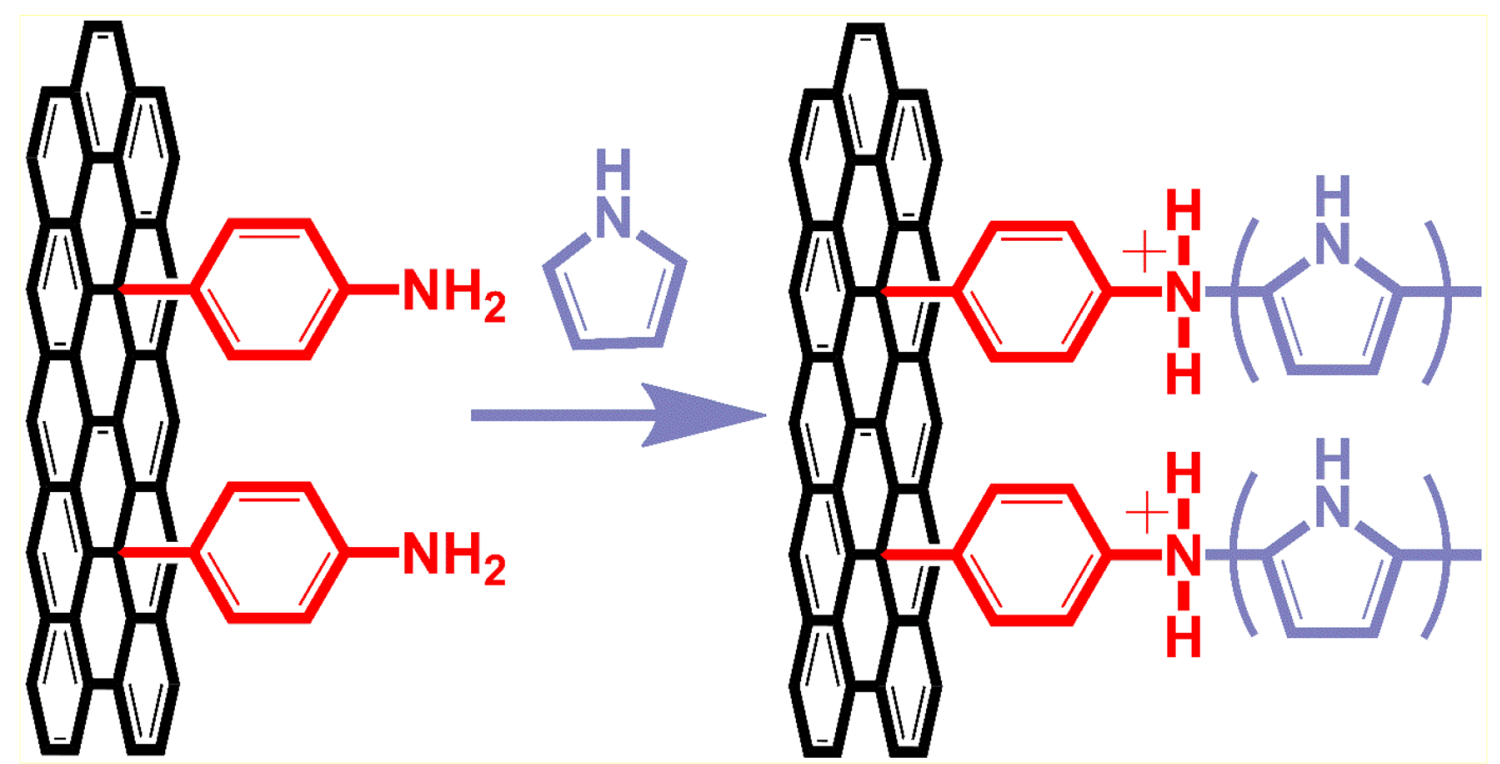

Fig. 17 Scheme for modified graphene nanosheets/PPy composite preparation and formation of covalent bonds between amino groups and pyrrole ring Adapted from reference [74] with permission of Elsevier)

tensile strength by $256 \%$ and caused an increase in the glass transition temperature by $37 \%$. The possibility of using a nanocomposite film as a protective layer to prevent corrosion of carbon steel, as well as an oil sensor, was also examined. There was a significant improvement in corrosion inhibition because the charge transfer resistance was $110 \times 106 \Omega \mathrm{cm}^{2}$ for the composite compared to $0.35 \times 106 \Omega \mathrm{cm}^{2}$ for the pure epoxy resin. The obtained results indicate potential applications of this type of composite as anti-corrosion sensors coatings. 


\subsubsection{Diazonium-Modified Cloisite/Poly(Glycidyl Methacrylate) Nanocomposite}

Cloisite filler was modified with diethyldithiocarbamate benzyl diazonium salt. Then this filler was used as an initiator in the polymerization of glycidyl methacrylate [63]. Nanocomposites were prepared by radical photopolymerization initiated by the aryl layer. Unfortunately, conductivity and mechanical properties for these materials were not tested.

\subsubsection{Diazonium-Modified Montmorillonite/Poly(Glycidyl Methacrylate) Nanocomposite}

The last example is the use of montmorillonite as a filler in poly (glycidyl methacrylate) [64]. Montmorillonite was modified with dimethylaminobenzenediazonium salt. Next was used as an initiator in the polymerization of the poly(glycidyl methacrylate). Conductivity, mechanical and thermal properties were not tested for these materials.

\subsection{Silica}

Silica that forms covalent bonds with the organic matrix was modified with in situ generated 4-hydroxymethyl benzene diazonium salt and used in phenol-formaldehyde resins [81, 82]. The main aim of the modification was to improve the mechanical properties of the composite and reduce the toxicity of the cross-linking agent. Diazonium modification allowed the incorporation of hydroxymethyl groups, which are responsible for cross-linking of the phenol-formaldehyde resin (Fig. 5). The determination of the flow distance evaluated the reactivity of the filler. The flow distance was reduced due to the addition of an active filler. That indicates the influence of filler on the cross-linking of the resin. The modified particles were evenly distributed in the composite, whereas large aggregates were visible for the unmodified filler. Differences were also visible for the model abrasive tools. Unmodified silica was visible on the surface of the abrasive grains, which indicated its poor mixing with the resin. The modified silica was not noticeable, which indicates that it was very well mixed. Flexural strength increased by $68 \%$ for the composite with modified filler compared to the unmodified filler and by $246 \%$ for abrasive tools. The increase in flexural strength was associated with the formation of covalent bonds between the resin and the modified filler. On the other hand, it was due to the better distribution of the filler in the tested composites. Materials with modified silica also had a higher cross-link density, as indicated by the higher storage modulus. Summarizing, the active filler improves the thermomechanical and mechanical properties of the novolac composites and model abrasive tools and may allow for extended use of these composites.

\subsection{Ruthenium Oxide/Titanium Dioxide/Polyaniline Nanocomposite}

Composite was prepared by in situ oxidative polymerization of aniline on diazonium-modified ruthenium oxide/titanium oxide heterostructure [83]. Mixed oxide nanoparticles were modified with a 4-diphenylamine diazonium salt. The composites were used to degrade methyl orange in the dark. The research confirmed that the addition of a modified filler increases the efficiency of degradation of methyl orange in the dark. Due to the composite's stability and the ability to be reused up to nine times without losing catalytic activity, it has potential in practical applications.

\subsection{Titanium Dioxide}

Modified titanium dioxide was used as a filler in a nanocomposite, whose matrix was polyaniline [84]. This nanocomposite was used to remove methyl orange dye. The functionalization of titanium dioxide was carried out using diazonium salt. During modification, an aryl layer with diphenylamine groups was created. The nanocomposites were prepared by in situ polymerization of aniline on titanium dioxide nanoparticles. Nanoparticles were grafted with 4-diphenylamine. In a first step, ammonium persulfate was added to the modified filler and aniline. This step leads to the formation of anilinium and diphenylamine cations. In the next step, monomers are attached to the activated layer to form a polyaniline layer (Fig. 8). The resulting composite with modified filler successfully catalyzed methyl orange degradation in an aqueous environment under UV light. Degradation was much higher for the nanocomposite with the modified filler $\left(0.133 \mathrm{~min}^{-1}\right)$ relative to pure titanium dioxide $\left(0.059 \mathrm{~min}^{-1}\right)$ as well as the nanocomposite with the unmodified filler $\left(0.085 \mathrm{~min}^{-1}\right)$. Also, the nanocomposite with modified filler can be recycled 5-times without loss of photocatalytic activity. The unmodified material can be recycled only 3-times, and pure $\mathrm{TiO}_{2}$ can only be reused once. This work emphasizes the vital role of diazonium salts in the design of new photocatalysts for the mineralization of organic dyes.

\subsection{Zeolite}

\subsubsection{Diazonium-Modified Zeolite/Phenol-Formaldehyde Composite}

Modified zeolite fillers were used in phenol-formaldehyde resins $[85,86]$. The purpose and scheme for zeolite are the same as shown for carbon black and silica (Fig. 5). Flexural strength increased for the composite with modified zeolite compared to the composite with unmodified filler. Composites also had better ability to dissipate mechanical energy, 
better damping properties, higher thermal stability, and, they are cross-linked in a shorter time. Thermogravimetric analysis-mass spectrometry results indicated no release of toxic urotropine degradation products from composites containing modified fillers. All these results benefits indicate the high potential of these fillers in abrasives.

\subsubsection{Diazonium-Modified Zeolite/Methacrylate Composite}

A composite with the modified filler was applied as an active filler in methacrylic-resin-based photocurable composites for potential use in dental applications [87]. The resins used in the study were bisphenol A-glycidyl methacrylate and triethylene glycol dimethacrylate. The zeolite was modified with a 4-dimethylamino benzene diazonium salt. Diazonium salt modification allows the incorporation of dimethylamino groups. These groups initiate the polymerization of bisphenol A-glycidyl methacrylate and triethylene glycol dimethacrylate (Fig. 18). It was shown that the modified filler had an impact on the cross-linking properties of the resin. The application of some amount of modified filler also affected the mechanical properties of a final composite. In almost all cases, the compressive and 3-point flexural strength of the studied composites was better or at least the same as it was in the case of unmodified-filler composites.

\section{Diazonium-Modified Fillers that Do Not Form Covalent Bonds with the Polymer}

The second group of fillers modified with diazonium salts is those that do not form covalent bonds with the polymer. Modification of the filler may affect the formation of hydrogen bonds between components. Furthermore, components can form a better distribution within the composite.

\subsection{Carbon Fiber}

Modified carbon fibers were used as a component of a composite with a polyester resin [46]. The filler was modified using 4-hydroxyl benzene diazonium salt and then copolymerized in situ with hexachlorocyclotriphosphazene and cardanol. The main aim was to change the microstructure of fiber surfaces and improve interfacial properties in the composite. Due to modification, the interlaminar shear strength of the composites with modified filler increased by $41 \%$ compared to composite with unmodified filler. Furthermore, the anti-hydrothermal ageing properties of the modified composites were significantly increased.

\subsection{Carbon Nanotubes}

The aim of using carbon nanotubes was to investigate the effect of filler modification on dispersion in poly(propylene fumarate). Furthermore, the influence of filler on the mechanical strengthening of the cross-linked nanocomposites was checked [54]. The modification was carried out using 4-tert-butylbenzenediazonium salt. Modified filler was dispersed better than unmodified in both the uncrosslinked and cross-linked poly(propylene fumarate) matrix. The nanocomposite with the modified filler was better than with the unmodified filler in terms of mechanical properties. The addition of the modified filler affected a threefold increase in compressive and flexural modulus and a twofold increase in compressive offset yield strength and flexural strength. Due to improved mechanical properties, these nanocomposites have great potential for the fabrication of bone tissue engineering scaffolds.

\subsection{Fullerene}

Fullerene that was modified with diazonium salt was used in composite membranes of sulfonated poly(ether ether ketone) [65]. The filler was modified using a diazonium salt having sulfonic acid groups in its structure. Due to the introduction of these groups on the surface of the filler, hydrogen bonds occurred between the filler and the matrix (Fig. 19). The composite membranes with modified filler showed improved stability due to the oxidation resistance of fullerene and the occurrence of interfacial hydrogen bonding. Moreover, composites with modified filler had better ion exchange capacity, water sorption, and proton conductivity in comparison to the pure polymer. Time evolution studies showed that the steady-state power densities for the composite with modified filler were higher than for pure polymer.

\subsection{Graphene}

\subsubsection{Diazonium-Modified Graphene/Polyaniline Composite}

Graphene was functionalized with diazonium salts of sulfanilic acid [69]. The composite was prepared by in situ polymerization of aniline in the presence of modified graphene. The modified graphene/polyaniline composite showed a 20 -fold higher electrical conductivity than the pure polymer. Moreover, the modified filler produces some change in the internal $\mathrm{pH}$ of the composite, making it electroactive at higher $\mathrm{pH}$ electrolytes. 
Fig. 18 Scheme for modified zeolite/methacrylic composite preparation and formation of covalent bonds Adapted from reference [87] with permission of Taylor \& Francis)
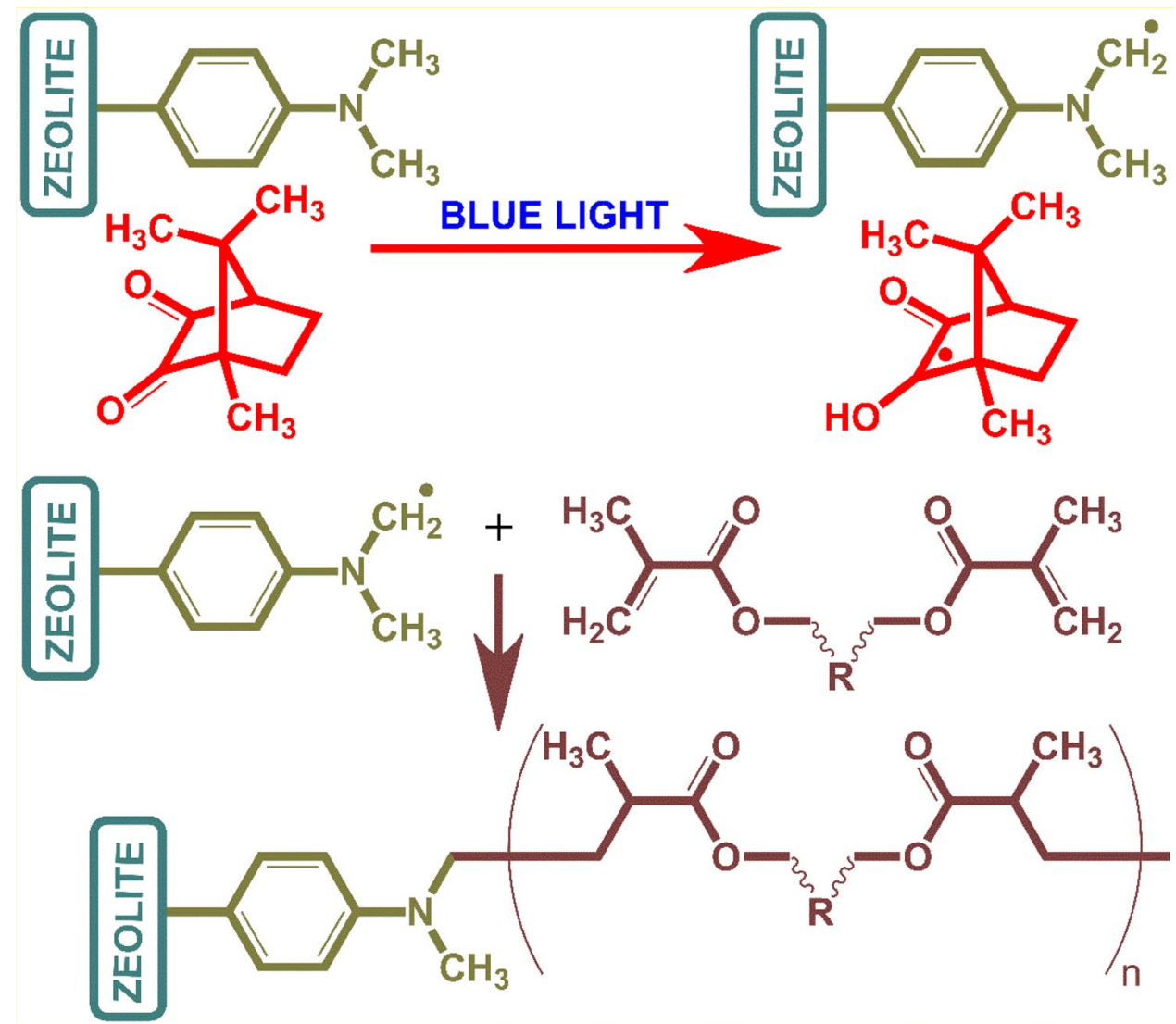

\subsubsection{Diazonium-Modified Graphene Oxide/ Polybenzimidazolium Composite}

Graphene oxide was functionalized with 4-(Tri- fluoromethylthiobenzenediazonium salt to improve dispersibility in composite [70]. The purpose of the work was to prepare mechanically robust and highly permselective anion exchange membranes. The results indicated that the filler was well dispersed in the matrix. The addition of a small amount of modified filler was shown to be beneficial to key properties such as mechanical strength and permeability. Composites with modified fillers have great potential as an electrodialysis material.

\subsubsection{Diazonium-Modified Graphene Oxide/Sulfonated Poly(Ether Ether Ketone) Composite}

Graphene oxide was modified with a diazonium salt, which contained sulfonate groups, to decrease the proton conduction barrier and improve the conduction properties of the composite [71]. Composites with modified filler had much better thermal stability, mechanical strength, dimensional stability, and proton conductivities. Moreover, that composite showed a maximum power density of $705 \mathrm{~mW} \mathrm{~cm}^{-2}$, indicating its potential in fuel cell applications.

\subsubsection{Diazonium-Modified Graphene Oxide/Polyimide Composite}

The next example of the use of modified graphene oxide was its application as a filler in a composite with polyimide [72]. The surface modification of graphene oxide was carried out with 4-iodobenzenediazonium salt. The composite with the modified filler had more than 100-times higher conductivity $(\sim 1 \mathrm{~S} / \mathrm{m})$ relative to an unmodified filler/composite. The electrical resistance of the composite film with modified filler was dramatically decreased along with tensile strain. The results of this work indicate the enormous potential of this type of material as a highly sensitive electromechanical strain sensor.

\subsubsection{Diazonium-Modified Graphene Oxide/ Polystyrene-Acrylonitrile Composite}

The surface modification of graphene oxide was carried out with the aryl diazonium salt of sulfanilic acid [78]. The storage modulus of the composite with the modified filler increased by $46 \%$ relative to the composite with unmodified filler. This improvement was attributed to strong interactions between sulfonated groups on the surface-modified graphene oxide and the nitrile groups of the polymer. 


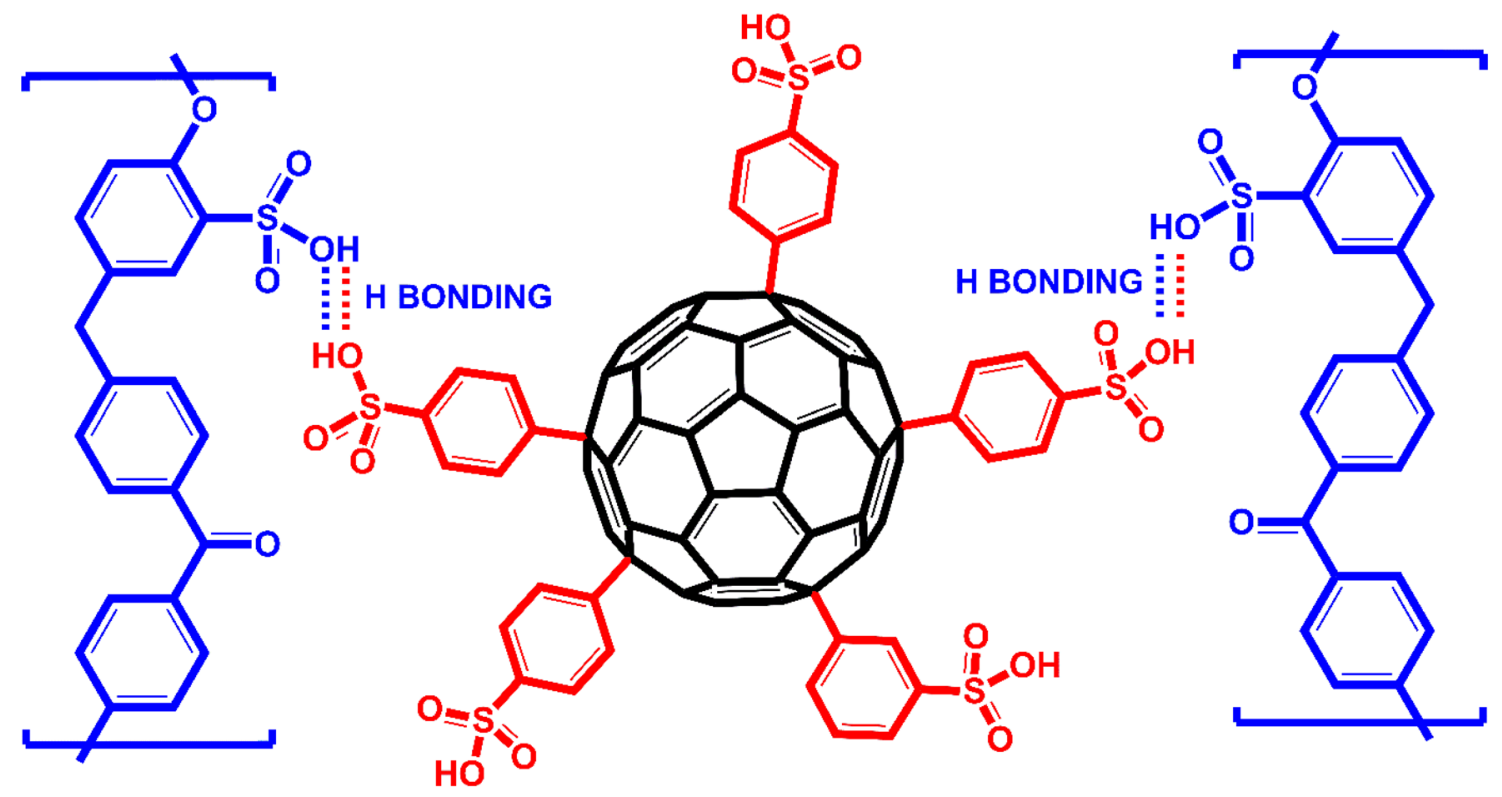

Fig. 19 Scheme for modified fullerene/sulfonated poly(ether ether ketone) composite preparation and the formation of hydrogen bonds Adapted from reference [65] with permission of Elsevier

\subsubsection{Diazonium-Modified Graphene Oxide/Poly(Vinyl Alcohol) Composite}

The surface modification of graphene oxide was carried out using a diazonium salt, which contained sulfonate groups [79]. The modification was attributed to the fact that graphene added to poly(vinyl alcohol) is unevenly distributed and forms agglomerates. Modified graphene oxide formed a better dispersion than pure graphene and graphene oxide. The results indicated that the crystallinity of composite with modified filler was superior to that of composite with unmodified probably due to the presence of hydrogen bonds. The addition of the modified filler improved electrical conductivity (100-fold), tensile strength (181\%), and modulus (198\%). Composites with modified filler also improved the thermal stability relative to composites with unmodified filler.

\subsubsection{Diazonium-Modified Graphene/Poly(Vinylidene Fluoride) Composite}

The last example of the graphene application presented in this work is the application in composites with poly(vinylidene fluoride) [80]. The surface modification was carried out using a diazonium salt with hydroxyl and carboxyl groups. These groups affect the formation of hydrogen bonds between the filler and the polymer (Fig. 19). The results indicate that the polar functional groups in the modified graphene significantly affect the dielectric properties of the composite. Tunable dielectric properties, low percolation threshold, and large energy density (up to $17 \mathrm{~J} \mathrm{~cm}^{-3}$ ) in the polymeric composites suggest strong chemical bonding between the filler and polymer matrix (Fig. 20). Composites with modified fillers should have great potential in modern electronics and electric power systems.

\subsection{Cellulose}

In the first study, the modified cellulose filler was abaca, while in the second sawdust [56, 57]. In both studies, fillers were modified with a benzene diazonium salt to improve the mechanical properties of the cellulose-polypropylene composites as a result of reducing the hydrophilicity of the cellulose present in the filler. It was found that the mechanical properties (tensile strength, Young's modulus, flexural strength, flexural modulus, impact strength) of composites with modified filler significantly increased relative to the composite with unmodified filler. It was also noted that the modified filler was better dispersed in the matrix, and the filled composite had a lower water absorption.

\section{Conclusion}

This review indicates a tremendous impact of filler modification using diazonium salts on the properties of composites. Modification using diazonium salts has been used to improve the properties of many fillers. These fillers have been used in many types of polymers. Fillers that create covalent bonds with the polymer and those that do not significantly improve 

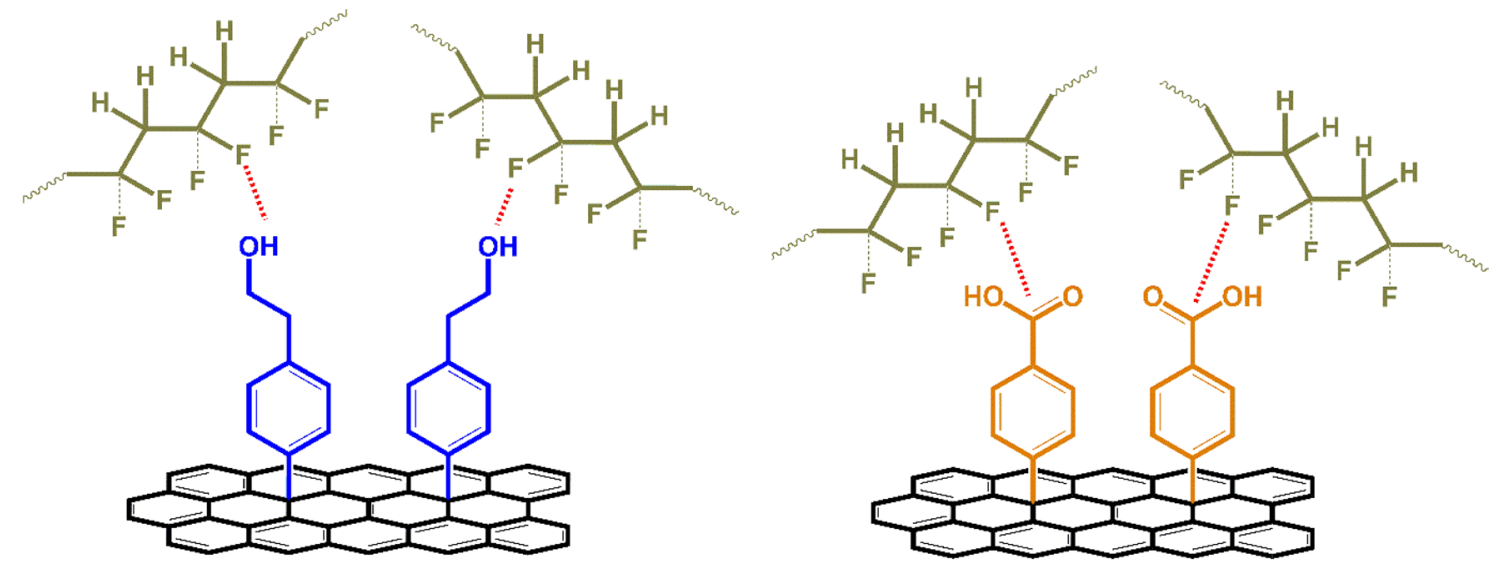

Fig. 20 Scheme for modified graphene/poly(vinylidene fluoride) composite preparation and formation of hydrogen bonds Adapted from reference [80] with permission of Elsevier

the properties of composites. The addition of a modified filler has improved such properties as thermal conductivity, thermal stability, and mechanical properties (e.g., interfacial shear strength, compressive strength, flexural strength). Materials based on modified fillers are likely to be widely used, e.g., in controlled drug release, as antistatic coatings, in electrode materials, as photocatalysts, as bone tissue engineering scaffolds, in fuel cell applications, as abrasive tools, and as electromechanical strain sensors. Many of the studies present interesting issues; however, the composites have not been fully and sufficiently characterized. In the presented studies, no attempt was made to determine the surface activity of the fillers. However, the surface activity of the fillers should play an essential role in the properties of the composites [89]. Changing surface activity affects the polymer-filler bonds and filler-filler interactions. The surface properties of the modified fillers can be easily tested using Inverse Gas Chromatography [90, 91]. The broader characterization of these fillers and their composites may reveal even more interesting properties.

In summary, modified fillers in composites demonstrate high potential for significant applications in a variety of fields and are worth further development. The results in some publications are not precise and broad. However, based on each publication, it can be partially assumed what effect the modification will have on the properties of the final composite. This review should help both academic and industrial scientists in the selection of fillers for given types of polymers and composites to obtain improved practical applications.

Acknowledgments This paper was produced with financial support from the Polish National Science Centre (Grant No. DEC-2019/32/T/ ST5/00209).
Open Access This article is licensed under a Creative Commons Attribution 4.0 International License, which permits use, sharing, adaptation, distribution and reproduction in any medium or format, as long as you give appropriate credit to the original author(s) and the source, provide a link to the Creative Commons licence, and indicate if changes were made. The images or other third party material in this article are included in the article's Creative Commons licence, unless indicated otherwise in a credit line to the material. If material is not included in the article's Creative Commons licence and your intended use is not permitted by statutory regulation or exceeds the permitted use, you will need to obtain permission directly from the copyright holder. To view a copy of this licence, visit http://creativecommons.org/licenses/by/4.0/.

\section{References}

1. V. Mévellec, S. Roussel, L. Tessier, J. Chancolon, M. MayneL'Hermite, G. Deniau, P. Viel, S. Palacin, Chem. Mater. 19, 6323 (2007)

2. Y. Xie, C.A.S. Hill, Z. Xiao, H. Militz, C. Mai, Composites A 41, 806 (2010)

3. S. Mallakpoura, M. Madania, Prog. Org. Coat. 86, 194 (2015)

4. A. Bensghaïer, F. Mousli, A. Lamouri, P.S. Postnikov, M.M. Chehimi, The Molecular and Macromolecular Level of Carbon Nanotube Modification Via Diazonium Chemistry: Emphasis on the 2010s Years, Chemistry Africa (2020)

5. P. Hu, S. Gao, Y. Zhang, L. Zhang, C. Wang, Compos. Sci. Technol. 156, 109 (2018)

6. P.C. Ma, J.K. Kim, B.Z. Tang, Carbon 44, 3232 (2006)

7. C.Y.K. Lung, J.P. Matinlinna, Dent. Mater. 28, 467 (2012)

8. H. Wu, W.P. Fahy, S. Kim, H. Kim, N. Zhao, L. Pilato, A. Kafi, S. Bateman, J.H. Koo, Prog. Mater. Sci. 111, 100638 (2020)

9. H. Hazimeh, S. Piogé, N. Pantoustier, C. Combellas, F.I. Podvorica, F. Kanoufi, Chem. Mater. 25, 605 (2013)

10. E.P. Plueddemann, J. Adhes. Sci. Technol. 5, 261-277 (1991)

11. S. Brase, S. Dahmen, C. Popescu, M. Schroen, F.J. Wortmann, Chem. Eur. J. 10, 5285 (2004)

12. S. Mahouche-Chergui, S. Gam-Derouich, C. Mangeney, M.M. Chehimi, Chem. Soc. Rev. 40, 4143 (2011)

13. D.J. Eyckens, F. Stojcevski, A. Hendlmeier, C.L. Arnold, J.D. Randall, M.D. Perus, L. Servinis, T.R. Gengenbach, B. Demir, T.R. Walsh, L.C. Henderson, Chem. Eng. J. 353, 373 (2018) 
14. M. Sheng, D. Frurip, D. Gorman, J. Loss Prevent. Proc. 38, 114 (2015)

15. N. Fei, B. Sautera, D. Gillingham, Chem. Commun. 52, 7501 (2016)

16. M.E. Trusova, K.V. Kutonova, V.V. Kurtukov, V.D. Filimonov, P.S. Postnikov, Resource Effic. Technol. 2, 36 (2016)

17. V.D. Filimonov, M. Trusova, P. Postnikov, E.A. Krasnokutskaya, Y. Min Lee, H.Y. Hwang, H. Kim, K.W. Chi, Org. Lett. 10(18), $3961(2008)$

18. A.A. Bondarev, E.V. Naumov, AZh Kassanova, E.A. Krasnokutskaya, K.S. Stankevich, V.D. Filimonov, Org. Process Res. Dev. 23, 2405 (2019)

19. V.D. Filimonov, E.A. Krasnokutskaya, AZh Kassanova, V.A. Fedorova, K.S. Stankevich, N.G. Naumov, A.A. Bondarev, V.A. Kataeva, Eur. J. Org. Chem. 4, 665 (2019)

20. A.A.L. Ahmad, B. Workie, A.A. Mohamed, Surfaces 3, 14 (2020)

21. S. Almheiri, A.A.L. Ahmad, B.L. Droumaguet, R. Pires, A.A. Mohamed, M.M. Chehimi, Langmuir 36, 74 (2020)

22. K. Jlassi, S. Zavahir, P. Kasak, I. Krupa, A.A. Mohamed, M.M. Chehimi, Energy Convers. Manag. 168, 170 (2018)

23. S.Q. Lud, M. Steenackers, R. Jordan, P. Bruno, D.M. Gruen, P. Feulner, J.A. Garrido, M. Stutzmann, J. Am. Chem. Soc. 128, 16884 (2006)

24. M.P. Stewart, F. Maya, D.V. Kosynkin, S.M. Dirk, J.J. Stapleton, C.L. McGuiness, D.L. Allara, J.M. Tour, J. Am. Chem. Soc. 126, 370 (2004)

25. B. Chen, A.K. Flatt, H. Jian, J.L. Hudson, J.M. Tour, Chem. Mater. 17, 4832 (2005)

26. A. Laforgue, T. Addou, D. Belanger, Langmuir 21, 6855 (2005)

27. Y.A. Atmane, L. Sicard, A. Lamouri, J. Pinson, M. Sicard, C. Masson, S. Nowak, P. Decorse, J. Piquemal, A. Galtayries, C. Mangeney, J. Phys. Chem. C 117, 26000 (2013)

28. A.E. Del Río Castillo, C.D. Reyes-Vazquez, L.E. Rojas-Martinez, S.B. Thorat, M. Serri, A.L. Martinez-Hernandez, C. Velasco-Santos, V. Pellegrini, F. Bonaccorso, FlatChem 18, 100131 (2019)

29. H. Dogan, E. Yildiz, M. Kaya, T.Y. Inan, Bull. Mater. Sci. 36(4), $563(2013)$

30. S. Gam-Derouich, S. Mahouche-Chergui, M. Turmine, J.Y. Piquemal, D.B. Hassen-Chehimi, M. Omastová, M.M. Chehimi, Surf. Sci. 605, 1889 (2011)

31. Z. Salmi, S. Gam-Derouich, S. Mahouche-Chergui, M. Turmine, M.M. Chehimi, Chem. Pap. 66(5), 369 (2012)

32. M. Sandomierski, T. Buchwald, B. Strzemiecka, A. Voelkel, Spectrochim. Acta A 191, 27 (2018)

33. M. Sandomierski, T. Buchwald, A. Voelkel, Surf. Coat. Technol. 385, 125389 (2020)

34. N. Delaporte, R.L. Belanger, G. Lajoie, M. Trudeau, K. Zaghib, Electrochim. Acta 308, 99 (2019)

35. D. Hetemi, V. Noël, J. Pinson, Biosensors 10, 4 (2020)

36. P.R. Marcoux, P. Hapiot, P. Batail, J. Pinson, New J. Chem. 28, $302(2004)$

37. A. Adenier, N. Barre, E. Cabet-Deliry, A. Chausse, S. Griveau, F. Mercier, J. Pinson, C. Vautrin-Ul, Surf. Sci. 600, 4801 (2006)

38. G. Zeb, P. Viel, S. Palacin, X.T. Le, RSC Adv. 5, 50298 (2015)

39. M. Busson, A. Berisha, C. Combellas, F. Kanoufi, J. Pinson, Chem. Commun. 47, 12631 (2011)

40. M.M. Chehimi, A. Lamouri, M. Picot, J. Pinson, J. Mater. Chem. C 2, 356 (2014)

41. D. Jiang, B.G. Sumpter, S. Dai, J. Phys. Chem. B 110(47), 23628 (2006)

42. A.A. Mohamed, Z. Salmi, S.A. Dahoumane, A. Mekki, B. Carbonnier, M.M. Chehimi, Adv. Colloid Interface 225, 16 (2015)

43. Aryl Diazonium Salts: New Coupling Agents in Polymer and Surface Science; Chehimi, M. M., Ed.; Wiley: Weinheim, Germany, 2012.
44. Z. Wang, Q. Li, Z. Chen, J. Liu, T. Liu, H. Li, S. Zheng, Ind. Eng. Chem. Res. 57, 11005 (2018)

45. M. Sandomierski, T. Buchwald, B. Strzemiecka, A. Voelkel, J. Appl. Polym. Sci. 137(3), 48160 (2020)

46. Y. Zheng, L. Chen, X. Wang, G. Wu, Polymers 12, 45 (2020)

47. L. Szabo, S. Imanishi, N. Kawashima, R. Hoshino, K. Takada, D. Hirose, T. Tsukegi, K. Ninomiya, K. Takahashi, RSC Adv. 8, 22729 (2018)

48. W. Liu, J. Kong, W.E. Toh, R. Zhou, G. Ding, S. Huang, Y. Dong, X. Lu, Compos. Sci. Technol. 85, 1 (2013)

49. F. Buffa, H. Hu, D.E. Resasco, Macromolecules 38, 8258 (2005)

50. Y. Martinez-Rubi, J.M. Gonzalez-Dominguez, A. Anson-Casaos, C.T. Kingston, M. Daroszewska, M. Barnes, P. Hubert, C. Cattin, M.T. Martinez, B. Simard, Nanotechnology 23, 285701 (2012)

51. A. Mekki, S. Samanta, A. Singh, Z. Salmi, R. Mahmoud, M.M. Chehimi, D.K. Aswal, J. Colloid Interf. Sci. 418, 185 (2014)

52. L. Pilan, M. Raicopol, A. Pruna, V. Branzoi, Surf. Interface Anal. 44, 1198 (2012)

53. J.M. Gonzalez-Dominguez, P. Castell, S. Bespin-Gascón, A. Ansón-Casaos, A.M. Diez-Pascual, M.A. Gómez Fatou, A.M. Benito, W.K. Maser, M.T. Martinez, J. Mater. Chem. 22, 21285 (2012)

54. X. Shi, J.L. Hudson, P.P. Spicer, J.M. Tour, R. Krishnamoorti, A.G. Mikos, Biomacromolecules 7, 2237 (2006)

55. A. Bensghaïer, Z. Salmi, B. Le Droumaguet, A. Mekki, A.A. Mohamed, M. Bejia, M.M. Chehimi, Surf. Interface Anal. 48 509 (2016)

56. R. Rahman, M. Huque, N. Islam, M. Hasan, Composites A 40, 511 (2009)

57. R. Rahman, N. Islam, M. Huque, J. Polym. Environ. 18, 443 (2010)

58. N. Islam, R. Rahman, M. Haque, M. Huque, Composite. Part A 41, 192 (2010)

59. R. Msaadi, S. Ammar, M.M. Chehimi, Y. Yagci, Eur. Polym. J. 89, 367 (2017)

60. R. Msaadi, G. Yilmaz, A. Allushi, S. Hamadi, S. Ammar, M.M. Chehimi, Y. Yagci, Polymers 11, 286 (2019)

61. K. Jlassi, S. Chandran, M.A. Poothanari, M. Benna-Zayani, S. Thomas, M.M. Chehimi, Langmuir 32, 3514 (2016)

62. K. Jlassi, A.B. Radwan, K.K. Sadasivuni, M. Mrlik, A.M. Abdullah, M.M. Chehimi, I. Krupa, Sci. Rep. 8, 13369 (2018)

63. H. Salmi-Mani, Z. Ait-Touchente, A. Lamouri, B. Carbonnier, J.F. Caron, K. Benzarti, M.M. Chehimi, RSC Adv. 6, 88126 (2016)

64. Z. Salmi, K. Benzarti, M.M. Chehimi, Langmuir 29, 13323 (2013)

65. G. Rambabu, S.D. Bhat, Electrochim. Acta 176, 657 (2015)

66. M. Liu, Y. Duan, Y. Wang, Y. Zhao, Mater. Des. 53, 466 (2014)

67. M. Fang, Z. Zhang, J. Li, H. Zhang, H. Lu, Y. Yang, J. Mater. Chem. 20, 9635 (2010)

68. J. Liu, L. Cui, N. Kong, C.J. Barrow, W. Yang, Eur. Polym. J. 50, 9 (2014)

69. E. Coskun, E.A. Zaragoza-Contreras, H.J. Salavagione, Carbon 50, 2235 (2012)

70. L. Cseri, J. Baugh, A. Alabi, A. Al. Hajaj, L. Zou, R.A.W. Dryfe, P.M. Budd, G. Szekely, J. Mater. Chem. A 6, 24728 (2018)

71. X. Qiu, T. Dong, M. Ueda, X. Zhang, L. Wang, J. Membr. Sci. 524, 663 (2017)

72. O.K. Park, M.G. Hahm, S. Lee, H.I. Joh, S.I. Na, R. Vajtai, J.H. Lee, B.C. Ku, P.M. Ajayan, Nano Lett. 12, 1789 (2012)

73. C. Valles, D.G. Papageorgiou, F. Lin, Z. Li, B.F. Spencer, R.J. Young, I.A. Kinloch, Carbon 157, 750 (2020)

74. X. Wang, T. Wang, C. Yang, H. Li, P. Liu, Appl. Surf. Sci. 287, 242 (2013)

75. M. Fang, K. Wang, H. Lu, Y. Yang, S. Nutt, J. Mater. Chem. 19, $7098(2009)$

76. M. Fang, K. Wang, H. Lu, Y. Yang, S. Nutt, J. Mater. Chem. 20, $1982(2010)$ 
77. Z. Xiong, T. Gu, X. Wang, Langmuir 30, 522 (2014)

78. T.D.T. Vu, V.H. Pham, S.H. Hur, J.S. Chung, Polym. Compos. 37, 44 (2016)

79. D.S. Yu, T. Kuila, N.H. Kim, J.H. Lee, Chem. Eng. J. 245, 311 (2014)

80. C. Yang, S.J. Hao, S.L. Dai, X.Y. Zhang, Carbon 117, 301 (2017)

81. M. Sandomierski, B. Strzemiecka, M.M. Chehimi, A. Voelkel, Langmuir 32, 11646 (2016)

82. M. Sandomierski, T. Buchwald, M. Barczewski, A. Voelkel, Polym. Test. 75, 373 (2019)

83. F. Mousli, A. Chaouchi, M. Jouini, F. Maurel, A. Kadri, M.M. Chehimi, Catalysts 9, 578 (2019)

84. F. Mousli, A. Chaouchi, S. Hocine, A. Lamouri, M.R. Vilar, A. Kadri, M.M. Chehimi, Appl. Surf. Sci. 465, 1078-1095 (2019)

85. M. Sandomierski, B. Strzemiecka, J. Grams, M.M. Chehimi, Adam Voelkel. Int. J. Adhes. Adhes. 85, 157 (2018)

86. M. Sandomierski, B. Strzemiecka, W. Koczorowski, M. Barczewski, M. Kasperkowiak, M. Pokora, B. Borek, M.M. Chehimi, A. Voelkel, Polym. Compos. 40(8), 3209 (2019)

87. M. Sandomierski, Z. Okulus, Adam Voelkel, Compos. Interface. 26(7), 643 (2019)

88. C. Combellas, D. Jiang, F. Kanoufi, J. Pinson, F.I. Podvorica, Langmuir 25, 286 (2009)

89. A. Schroder, M. Kluppel, R.H. Schuster, Macromol. Mater. Eng. 292, 885 (2007)
90. A. Voelkel, B. Strzemiecka, K. Milczewska, Z. Okulus, Open Chem. 13, 893 (2015)

91. A. Voelkel, Chemom. Intell. Lab. Syst. 72, 205 (2004)

Publisher's Note Springer Nature remains neutral with regard to jurisdictional claims in published maps and institutional affiliations.

M. Sandomierski PhD, Poznań University of Technology, Poznań, Poland graduated from Faculty of Chemical Technology PUT in 2020. Involved in the development of the use of diazonium salts in surface modification of materials used in composites and biomedical applications. Currently, he is the author of 20 publications.

A. Voelkel Professor, Poznań University of Technology, Poznań, Poland graduated from Faculty of Chemical Technology PUT in 1976. Involved in the development and application of inverse gas chromatography and other chromatographic techniques in physicochemical characterization of various materials. Recently part of his group works on characterization of biomaterials including dental fillings, modified ceramic materials. He is the author of approx. 200 papers including chapters in several books. 